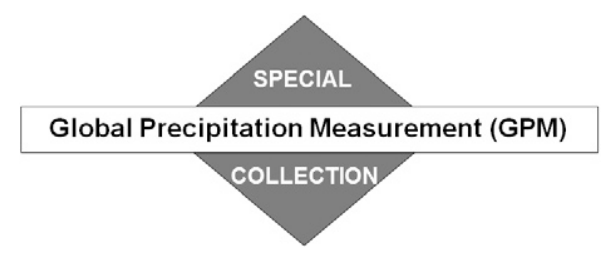

\title{
Satellite Estimation of Falling Snow: A Global Precipitation Measurement (GPM) Core Observatory Perspective ${ }^{\mathfrak{O}}$
}

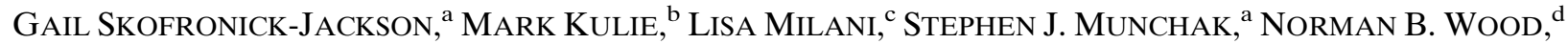 \\ AND VINCENZO LEVIZZANI ${ }^{\mathrm{c}}$ \\ ${ }^{\mathrm{a}}$ NASA Goddard Space Flight Center, Greenbelt, Maryland \\ ${ }^{\mathrm{b}}$ NOAA/NESDIS/STAR/Advanced Satellite Products Branch, Madison, Wisconsin \\ ${ }^{\mathrm{c}}$ National Research Council of Italy, Institute of Atmospheric Sciences and Climate, Bologna, Italy \\ ${ }^{\mathrm{d}}$ Space Science and Engineering Center, University of Wisconsin-Madison, Madison, Wisconsin
}

(Manuscript received 4 May 2018, in final form 31 March 2019)

\begin{abstract}
Retrievals of falling snow from space-based observations represent key inputs for understanding and linking Earth's atmospheric, hydrological, and energy cycles. This work quantifies and investigates causes of differences among the first stable falling snow retrieval products from the Global Precipitation Measurement (GPM) Core Observatory satellite and CloudSat's Cloud Profiling Radar (CPR) falling snow product. An important part of this analysis details the challenges associated with comparing the various GPM and CloudSat snow estimates arising from different snow-rain classification methods, orbits, resolutions, sampling, instrument specifications, and algorithm assumptions. After equalizing snow-rain classification methodologies and limiting latitudinal extent, CPR observes nearly 10 (3) times the occurrence (accumulation) of falling snow as GPM's Dual-Frequency Precipitation Radar (DPR). The occurrence disparity is substantially reduced if CloudSat pixels are averaged to simulate DPR radar pixels and CPR observations are truncated below the 8-dBZ reflectivity threshold. However, even though the truncated CPR- and DPR-based data have similar falling snow occurrences, average snowfall rate from the truncated CPR record remains significantly higher $(43 \%)$ than the DPR, indicating that retrieval assumptions (microphysics and snow scattering properties) are quite different. Diagnostic reflectivity $(Z)$-snow rate $(S)$ relationships were therefore developed at $\mathrm{Ku}$ and $\mathrm{W}$ band using the same snow scattering properties and particle size distributions in a final effort to minimize algorithm differences. CPR-DPR snowfall amount differences were reduced to $\sim 16 \%$ after adopting this diagnostic $Z-S$ approach.
\end{abstract}

\section{Introduction and background}

Observations of the global distributions of falling snow are needed for a wide variety of scientific and societal applications. For example, falling snow observations can be used to evaluate global change precipitation science predictions (Karl et al. 2009; Gergel et al. 2017; Harpold and Kohler 2017) and are needed for assessing inputs to snowpack water reserves (Lettenmaier et al. 2015). While most of the societal needs for falling snow

Supplemental information related to this paper is available at the Journals Online website: https://doi.org/10.1175/JAMC-D-18-0124.s1.

Corresponding author: Gail Skofronick-Jackson, gail.s.jackson@ nasa.gov measurements are important over land surfaces, falling snow over oceans and lakes represents a loss to capturing that water for resources and can affect the water body characteristics by changing the salinity and/or water temperature (Kattsov and Walsh 2000; Holland et al. 2007). Since it is difficult to measure global precipitation from ground-based observations (Kidd et al. 2017), satellite observations are required (e.g., Levizzani et al. 2011). The Tropical Rainfall Measuring Mission (TRMM) and other satellite precipitation sensors have shown the value of satellite-based global rain observations (Hou et al. 2014). Now there is great interest in hydrological investigations with global falling snowrate products to help close the atmospheric inputs to the water cycle (Field and Heymsfield 2015; Rodell et al. 2015) and to study snowpack patterns and growth 
TABLE 1. CloudSat and GPM instrument and orbit characteristics.

\begin{tabular}{|c|c|c|c|c|}
\hline & \multirow[b]{2}{*}{ CPR } & \multicolumn{2}{|c|}{ DPR } & \multirow[b]{2}{*}{ GMI } \\
\hline & & KuPR & $\mathrm{KaPR}$ & \\
\hline Frequency & $94 \mathrm{GHz}$ & $13.6 \mathrm{GHz}$ & $35.5 \mathrm{GHz}$ & $\begin{array}{c}\text { From } 10.65 \text { to } 183.31 \mathrm{GHz} \\
\left(13 \text { channels }^{\mathrm{a}}\right)\end{array}$ \\
\hline Footprint size & $\sim 1.7 \mathrm{~km} \times 1.4 \mathrm{~km}$ & \multicolumn{2}{|c|}{$5.05-5.60 \mathrm{~km}$ of diameter } & From $\sim 6$ to $\sim 26 \mathrm{~km}$ \\
\hline Near surface bin & $\sim 720-1200 \mathrm{~m}$ & $\sim 750-2500 \mathrm{~m}$ & $\sim 750-2500 \mathrm{~m}$ & - \\
\hline Sensitivity & $\sim-29 \mathrm{dBZ}$ & $\sim 12-13 \mathrm{dBZ}$ & $\begin{array}{l}\sim 12-13 \mathrm{dBZ}(\mathrm{HS}) \\
\sim 17-18 \mathrm{dBZ}(\mathrm{MS})\end{array}$ & $\begin{array}{c}\text { Noise equivalent delta temperatures } \\
\text { range from } 0.3-0.8 \mathrm{~K}\end{array}$ \\
\hline Scanning mode & Nadir pointing & Cross track & Cross track & Conical \\
\hline Range gate interval & $240 \mathrm{~m}^{\mathrm{b}}$ & $250 \mathrm{~m}$ & $250 \mathrm{~m}(\mathrm{MS}), 500 \mathrm{~m}(\mathrm{HS})$ & - \\
\hline Swath width & $1.4 \mathrm{~km}$ & $245 \mathrm{~km}$ & $125 \mathrm{~km}$ & $885 \mathrm{~km}$ \\
\hline Orbital altitude & $705 \mathrm{~km}$ & $407 \mathrm{~km}$ & $407 \mathrm{~km}$ & $407 \mathrm{~km}$ \\
\hline Orbit & Polar orbit & $\begin{array}{c}\text { Non-sun-synchronous } \\
\text { at } 65^{\circ} \text { inclination }\end{array}$ & $\begin{array}{c}\text { Non-sun-synchronous } \\
\text { at } 65^{\circ} \text { inclination }\end{array}$ & $\begin{array}{c}\text { Non-sun-synchronous } \\
\text { at } 65^{\circ} \text { inclination }\end{array}$ \\
\hline
\end{tabular}

${ }^{\mathrm{a}}$ The GMI channels in $\mathrm{GHz}$ are $10.65 \mathrm{~V}$ and $\mathrm{H}, 18.7 \mathrm{~V}$ and $\mathrm{H}, 21.8 \mathrm{~V}, 36.5 \mathrm{~V}$ and $\mathrm{H}, 89 \mathrm{~V}$ and $\mathrm{H}, 166 \mathrm{~V}$ and $\mathrm{H}, 183.31 \pm 3 \mathrm{~V}$, and $183.31 \pm$ $7 \mathrm{~V}$, where $\mathrm{V}(\mathrm{H})$ means vertical (horizontal) polarization.

${ }^{\mathrm{b}}$ Actual range gate spacing is approximately $480 \mathrm{~m}$ but measurements are oversampled to provide data at $240 \mathrm{~m}$ spacing.

(Palerme et al. 2014; Boening et al. 2012; Margulis et al. 2016; Wrzesien et al. 2018).

Currently there are two National Aeronautics and Space Administration (NASA) spaceborne platforms with instruments capable of observing falling snow: CloudSat (Stephens et al. 2002, 2008) and the Global Precipitation Measurement (GPM) mission (Hou et al. 2014; Skofronick-Jackson et al. 2017). CloudSat, launched in 2006, carries a single instrument, the W-band $(94 \mathrm{GHz})$ nadir-pointing Cloud Profiling Radar (CPR; Tanelli et al. 2008), in a near-polar ( $98^{\circ}$ inclination) sun-synchronous orbit. The CPR, while designed as a cloud-observing radar, is also capable of sensing light to moderate rain and falling snow. GPM, launched in 2014, was specifically designed to measure both liquid precipitation and falling snow using both the Dual-Frequency Precipitation Radar (DPR) with a Ka and Ku band radar built by the Japan Aerospace Exploration Agency (JAXA) and Japan's National Institute of Information and Communications Technology (NICT) (Toyoshima et al. 2015) and the GPM Microwave Imager (GMI) radiometer (Draper et al. 2015; Wentz and Draper 2016). Specifications for CPR, DPR, and GMI are provided in Table 1 along with orbital characteristics for GPM and CloudSat.

Joint evaluations of GPM and CloudSat global snowfall products are natural investigative pathways to explore, especially as an avenue for assessing and improving the products, but caution must be used when comparing these datasets. The products developed by the GPM and CloudSat missions for the three sensors of interest in this study (DPR, GMI, and CPR) employ disparate surface precipitation phase discrimination/ classification schemes in mission-affiliated official products, thus complicating comparison efforts (Casella et al. 2017). Orbital and resolution differences between CPR and DPR cause sampling dissimilarities that affect statistical analyses (e.g., Behrangi et al. 2012). The performance characteristics of the instruments, most notably the radar minimum detectable reflectivity values, also cause differences. Further, the respective radar observations are contaminated by range gate clutter near Earth's surface, and therefore nearsurface range gates above possible ground clutter (socalled near-surface bins) are used to estimate surface snowfall rates. Systematic differences in the near-surface bin designation between these sensors are evident and arise in part because of DPR scanning capabilities versus CPR fixed-nadir observations and other algorithmspecific considerations (Casella et al. 2017). Differences in the algorithm methodologies and a priori assumptions needed because of the underconstrained nature of the retrievals are another challenge in comparing falling snow products. The microphysical and associated scattering properties that drive the relationships between snowfall rate and radar reflectivity vary by radar wavelength and snow microphysical regime (e.g., Sekhon and Srivastava 1970; Leinonen et al. 2012; Heymsfield et al. 2016). As a result, the reflectivity-snow rate $(Z-S)$ relationships employed in radar-based algorithms, either explicitly or implicitly, depend on the particular assumptions about microphysical properties and their uncertainties that are made within the algorithms. For passive microwave retrievals as from GMI, snowfall 
estimates can also be affected by variable surface emissivity, especially over snow-covered surfaces. The land surface variable emissivity hinders falling snow detection compared to oceanic backgrounds that have lower and more uniform emissivities (Skofronick-Jackson et al. 2013), especially when compared to direct radar measurements. Indeed, a seasonal study of GMI falling snow retrievals has indicated a dependence on snow-cover characteristics (Ebtehaj and Kummerow 2017). GMI, however, has high frequencies $(166$ and $183 \mathrm{GHz})$ that have been shown to be particularly useful for falling snow estimates (Panegrossi et al. 2017).

Datasets composed of near-coincident DPR-CPR observations have been recently developed (Turk 2016; Yin et al. 2017). Global snowfall studies that adjusted for some of the complicating factors previously reported have been performed using these datasets (Casella et al. 2017; Tang et al. 2017). These analyses show that CPR observes more light snowfall events than DPR, while the DPR snowfall detections exceed those from CPR for higher intensity events (Casella et al. 2017; Tang et al. 2017) — not unexpected results given the respective radar sensitivities (Table 1). Furthermore, near-coincident snowfall rates from each dataset are poorly correlated, and DPR underestimates the total snow volume compared to CPR (Tang et al. 2017; Casella et al. 2017). Proposed methods to increase DPR signal fidelity near its minimum detectable threshold can reduce this gap significantly (Casella et al. 2017). The DPR, however, observes snowfall events in some regions more effectively than the CPR (e.g., some mountainous regions), presumably because of DPR scanning capabilities compared to CPR nadir-only observations (Tang et al. 2017). The DPR also shows a much broader latitudinal snowfall distribution compared to CPR (Tang et al. 2017). However, this latitudinal feature is probably due to phase discrimination disparities between the two datasets-a topic that will be discussed further in this study.

While the Turk (2016) and Yin et al. (2017) coincident datasets provide specific examples of snowfall events observed by the CPR versus DPR and GMI, these databases do not contain enough samples for robust statistics at high to low snow rates all around Earth. Casella et al. (2017) report about 35000 snowfall profiles in the matched GPM-CloudSat dataset composed of the first $\sim 14$ months of the GPM mission. Most of these profiles were confined to latitudes exceeding $60^{\circ} \mathrm{N}$ because of the combination of GPM sampling frequency near its latitudinal apex $\left(65^{\circ} \mathrm{N}\right)$ and a CloudSat Northern Hemispheric observational bias due to CloudSat daytime-only operations since 2011. The matched GPMCloudSat dataset is therefore not entirely geographically representative of global snowfall. Thus, the matched
GPM-CloudSat database is not used herein; instead level 2 (instantaneous swath) retrieval products are utilized.

The most recent and stable falling snow estimates from GPM (version 05, released May 2017) are compared to CloudSat (release R04) products for a multiyear period spanning the first 3 years of the GPM mission. This analysis differs from prior work by comparing active and passive estimates, but more importantly it focuses the analysis efforts on the product differences arising from classification, instrumentation, sampling, and algorithm differences to provide a more informative falling snow comparison. Section 2 provides information on the GPM datasets and the various falling snow products from GPM and CloudSat. Section 3 describes CloudSat and GPM product differences that are not related to underlying algorithm assumptions and ways to mitigate these differences. Section 4 provides a methodology to reduce $Z-S$ differences for the CPR and DPR retrievals and thus allow the adequacy of the mitigations described in section 3 to be evaluated. Section 5, discussion and conclusions, provides a summary of the work and delves into the implications of the comparison challenges, followed by next steps and conclusions. For quick reference, a comprehensive list of acronyms is provided in the appendix.

\section{GPM datasets and falling snow products}

GPM level 2 instantaneous swath precipitation retrievals are analyzed from the GMI, the DPR, and the combined DPR-GMI products. Because of DPR's instrument configuration and scanning strategy, it produces falling snow estimates across the $245-\mathrm{km}$ swath for normal scan (NS) with the Ku band, and across the 125-km Ka inner swath for both the $\mathrm{Ku}+\mathrm{Ka}$ matched scan (MS) and the high-sensitivity (HS) mode with the Ka channel (Kojima et al. 2012). In addition, there are falling snow estimates from GMI [Goddard profiling algorithm (GPROF); Kummerow et al. 2015] and from the combined radar-radiometer algorithm (CORRA or CMB; Grecu et al. 2016). A summary of the six GPM snow products, along with the CloudSat product, is given in Table 2. These products are not totally independent, but there are important differences that are noted in the information on the algorithms presented below.

GPROF is a physically based Bayesian retrieval of hydrometeor profiles, selected from an a priori database, that best fit the 13 channels of the GMI data. Each hydrometeor profile is associated with a surface precipitation rate. GPROF retrieves all parameters using the estimated expected value (a Bayesian method) described in Kummerow et al. $(2011,2015)$. The a priori Bayesian database used by GPROF is constructed by pairing observed DPR and CORRA precipitation estimates 
with the GMI brightness temperature observations. For version 05 of the GPROF algorithm, approximately 1 year of GPM observations are contained in the a priori database. To distinguish liquid precipitation from falling snow, the Sims and Liu (2015) technique is implemented that relies on the 2-m wet-bulb temperature (T2m). Acknowledging DPR's limitations in estimating light precipitation and discovering that the high-frequency (166-183 GHz) channels of GMI show a response to this lighter precipitation in mid- and high latitudes, GPROF has augmented its a priori database using CloudSat and Multi-Radar Multi-Sensor (MRMS; Zhang et al. 2016) data to improve light precipitation estimation.

The GPM DPR and CORRA precipitation algorithms convert the DPR measured reflectivity $(Z)$ profiles to precipitation particle size distribution (PSD) profiles, from which precipitation rate and water content can be obtained. These algorithms differ in their a priori assumptions regarding the PSD, additional information (besides the $Z$ profile) that is used to constrain the retrieval, and scattering models that are used to simulate $Z$ given the PSD. The DPR algorithms model the PSD as a three-parameter gamma distribution, although in practice, the shape parameter is fixed and the slope and intercept parameters are constrained to follow a rain-rate-median mass diameter $\left(R-D_{m}\right.$ or $S-D_{m}$, in the case of snow) power-law relationship, whereas the CORRA algorithm fixes both the shape parameter and normalized intercept $\left(N_{w}\right)$. Both algorithms condition the a priori relationships on the profile classification (convective versus stratiform) as well as geographic considerations (e.g., over ocean vs land). The DPR algorithms modify the $R-D_{m}$ relationship to obtain consistency with the path-integrated attenuation, and in the case of the MS products, the Ka-band reflectivity profile. Likewise, CORRA modifies $N_{w}$ to obtain better consistency with the path-integrated attenuation (PIA), Ka-band reflectivities, and GMI radiances. Version 05 of CORRA uses scattering tables derived from simulations of scattering from realistically shaped pristine and aggregate snowflakes (Kuo et al. 2016), which have been demonstrated to improve active-passive forward modeling consistency relative to low-density spherical scattering models (Olson et al. 2016). In classifying precipitation as liquid or frozen throughout the vertical column of radar observations, DPR uses brightband detection augmented with modeled temperature profiles.

The CloudSat snow profile product (2C-SNOWPROFILE) (2CSP) release R04 product (Wood 2011; Wood and L'Ecuyer 2013) used in this study provides estimates of snowfall characteristics for each observed profile that appears to contain snow reaching the surface. Reflectivity profiles are affected by ground clutter in the range bins nearest the surface, creating a so-called 

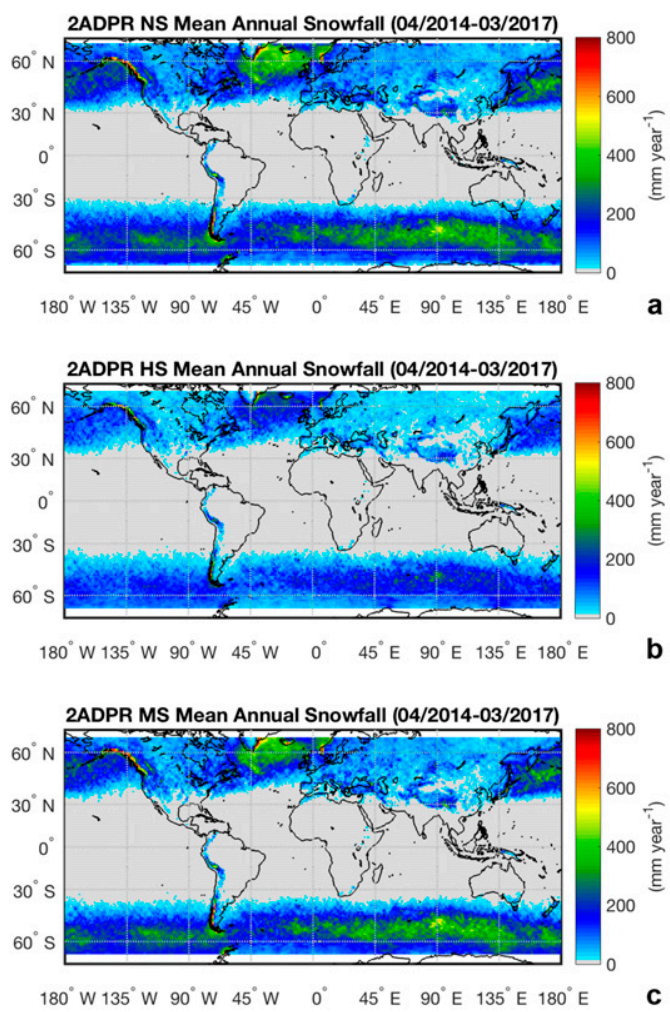

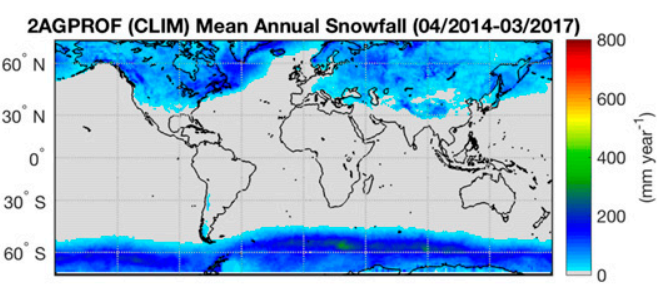

$180^{\circ} \mathrm{W} 135^{\circ} \mathrm{W} 90^{\circ} \mathrm{W} 45^{\circ} \mathrm{W} \quad 0^{\circ} \quad 45^{\circ} \mathrm{E} \quad 90^{\circ} \mathrm{E} 135^{\circ} \mathrm{E} 180^{\circ} \mathrm{E}$ d
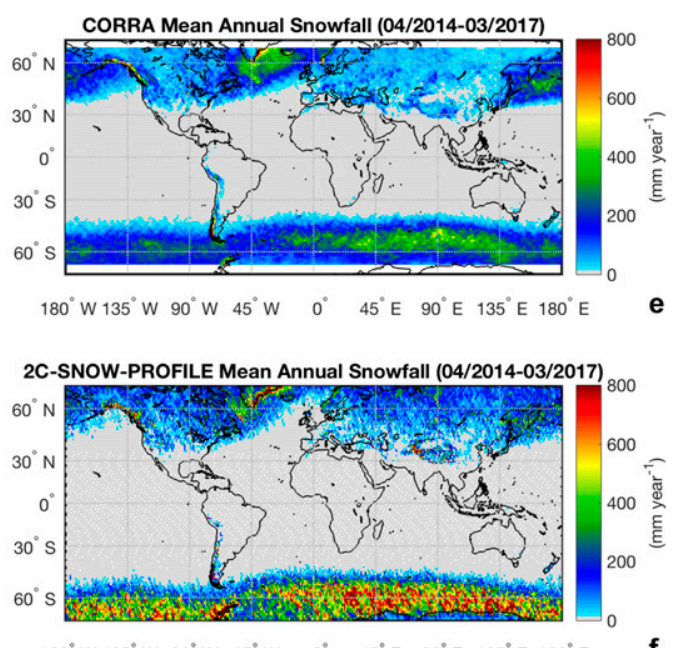

$180^{\circ} \mathrm{W} 135^{\circ} \mathrm{W} \quad 90^{\circ} \mathrm{W} \quad 45^{\circ} \mathrm{W} \quad 0^{\circ} \quad 45^{\circ} \mathrm{E} \quad 90^{\circ} \mathrm{E} \quad 135^{\circ} \mathrm{E} \quad 180^{\circ} \mathrm{E} \quad \mathbf{f}$

FIG. 1. GPM and CloudSat mean annual snowfall estimates $\left(\mathrm{mm} \mathrm{yr}^{-1}\right.$ ) for: (a) DPR Ku NS, (b) DPR Ka HS, (c) DPR Ku + Ka MS, (d) GMI GPROF, (e) Combined DPR + GMI CORRA, and (f) CloudSat 2CSP. Observations from April 2014 through March 2017 are used.

blind zone for CPR of about $1 \mathrm{~km}$ near the surface where valid reflectivity measurements are not possible. Surface snow is classified primarily by the CloudSat 2C precipitation column algorithm (2C-PRECIP-COLUMN) (2CPC) product (Haynes et al. 2009) based on the strength of the radar reflectivity in the radar bin just above the blind zone (the near-surface bin), the estimated height of the melting level above the surface, and a model for the rate of snow particle melting. If 2CPC indicates that snow at the surface is "likely" or "possible" and the melting-level height is such that the melted mass fraction at the surface is less than about $15 \%$, the 2CSP algorithm performs a retrieval. The algorithm first retrieves estimates of vertically resolved snow PSD parameters. The retrieval is performed using a Bayesian, optimal estimation (OE; Rodgers 2000) technique applied to the reflectivity profiles, supplemented with the reanalysis temperature profiles and a priori information about snow PSDs and microphysical properties. PSDs are assumed to be exponential with varying intercept and slope parameters. The a priori PSD information uses temperaturedependent estimates of the PSD parameters along with their covariances. The a priori microphysical properties include mass-dimension and projected area-dimension power laws whose parameter values and uncertainties are described using Gaussian probability distribution functions (Wood et al. 2014, 2015). The algorithm uses the retrieved PSD profiles along with the a priori microphysical properties to determine vertically resolved profiles of snowfall rate and water content within the retrieved layer. The surface snowfall rate is estimated simply as the snowfall rate in the near-surface bin.

Figure 1 shows the GPM and CloudSat 2CSP level 2 mean annual snowfall rates calculated directly from the standard products, publicly accessible from each mission's data center (see Table 2), for the 3-yr period April 2014March 2017. There are some obvious and subtler differences between the snow amounts shown in Fig. 1 due to several reasons including instrument capabilities, sampling, snow-rain classification, and algorithm methodologies. While the details of these differences will be provided in section 3, Figs. 1a-c (DPR NS, DPR HS, DPR MS) indicate more snow over the Gulf of Alaska and Fig. 1f (2CSP) has more snow in the Southern Ocean and Antarctic regions. Other subtle differences between the snow products are found in high mountainous areas (e.g., Greenland, the Andes, and the Himalayas). 

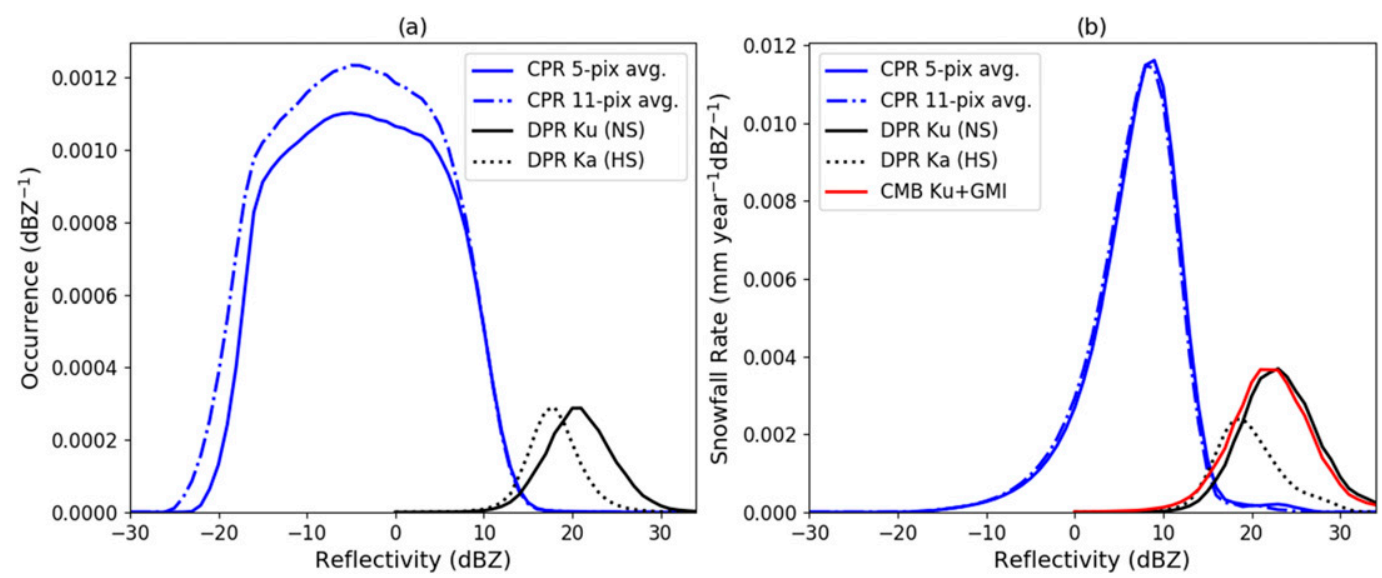

FIG. 2. Probability distribution function of CPR and DPR calibrated reflectivities using data from April 2014March 2017 for snow-only (a) reflectivity occurrence in $\mathrm{dB} Z^{-1}$, and (b) snowfall rate in $\mathrm{mm} \mathrm{day}^{-1} \mathrm{dBZ} Z^{-1}$.

More direct observations than the snowfall rates from CPR and DPR are the calibrated reflectivities. Figure 2 provides the probability distribution functions for DPR $\mathrm{Ku}, \mathrm{DPR} \mathrm{Ka}$ [in high-sensitivity (HS) mode], and CPR $\mathrm{W}$ reflectivities. For the CPR, these reflectivities are provided by the CloudSat geometric profile product (2B-GEOPROF; Marchand et al. 2008) and are those from the near-surface bin. They have been corrected for gaseous attenuation and for path-integrated hydrometeor attenuation as estimated by the 2C-PRECIPCOLUMN product (Haynes et al. 2009). In Fig. 2a at W band, reflectivities for snow tend to saturate near $20 \mathrm{dBZ}$ likely because of reduced backscattering efficiency of larger aggregates relative to lower frequencies and effects of hydrometeor attenuation and multiple scattering in heavier, deeper snow events (e.g., Kuo et al. 2016; Matrosov and Battaglia 2009). Meanwhile Fig. 2b implies that the DPR minimum detectable reflectivities for snow events are around $12-\mathrm{dBZ} \mathrm{Ku}$ and $\mathrm{Ka}$ (in $\mathrm{HS}$ mode), which correspond to the DPR design features. Figure 2a shows a systematic transition in the reflectivity distributions where DPR counts exceed CPR counts in the $12-14-\mathrm{dB} Z$ range. There is nothing surprising about Fig. 2 as CPR and DPR were designed for very different observations: CPR for small cloud particles and DPR for precipitation-sized particles. GPM's nonsun-synchronous orbit was designed to observe falling precipitation in the tropics and midlatitudes. The lower frequencies, at which the DPR radars operate, while necessary to avoid severe attenuation in heavier midlatitude and tropical precipitation, require larger instruments, where weight and power consumption becoming limiting design factors to improving $\mathrm{dBZ}$ sensitivity. Multiple scattering and attenuation effects may partially offset each other (Matrosov and Battaglia 2009), but the relative importance of multiple scattering versus attenuation for various radar wavelengths is not yet fully quantified because of scattering and extinction uncertainties that depend on highly variable microphysical properties (e.g., snow particle shape and size distribution) and because of three-dimensional cloud structure. The scanning nature of the DPR also reduces the dwell time, as compared to the CPR, for integration of the signal to obtain lower minimum detectable reflectivities. These differences in sensor requirements and resultant instrumentation design lead to differing capabilities between the DPR and the CPR to estimate light to heavy snow rates.

Of the three DPR products (NS, MS, and HS), only the DPR MS product relies on the combined $\mathrm{Ku}+\mathrm{Ka}$ bands. Because of the narrow swath, these MS products are near nadir $\left( \pm 9^{\circ}\right)$ observations, where ground clutter is less problematic and the measurements can be made closer to the surface. The MS product uses both $\mathrm{Ku}+\mathrm{Ka}$ bands allowing for including the more-sensitive $\mathrm{Ku}$ measurements down to $\sim 13 \mathrm{~dB} Z$ augmented by Kaband data where the snow is intense enough to produce reflectivities above $18 \mathrm{dBZ}$. Therefore, only the DPR MS product will be shown in future figures.

\section{GPM and CloudSat falling snow product differences}

This section details factors that likely contribute to differences between the GPM and CloudSat falling snow products, but that can be mitigated in an effort to make comparisons between radar-based products as equitable as possible. The product differences result from four main sources: classification, sampling, instrumentation sensitivity, and algorithmic differences. Classification refers to the method used to determine if a given profile is rain or snow at the surface. Sampling differences due 
to differing orbits, swath widths, and resolutions cause additional disparities between the products. The instruments, both radars and microwave radiometers, have different design features, most notably radar minimum detectable reflectivity (MDR) and radiometer frequency sensitivities as described above. Furthermore, radars such as the DPR and CPR resolve measurements into vertical range gates whereas radiometers like GMI measure a column-integrated signal. Even if all of these factors can be mitigated, differences in algorithm formulation and assumptions lead to dissimilarities that are more difficult to reconcile. One approach to put DPR and CPR estimates on a common basis, compensating for algorithmic differences, will be presented in section 4 .

As a note, in subsequent sections, efforts to minimize product differences are limited to DPR and CPR products, mostly because it is more straightforward to work with similar radar datasets. GMI products are not altered since GPROF retrievals use an a priori database directly linked to radar-derived snowfall rates (see section 2), thus complicating GPROF algorithm sensitivity tests. GMI GPROF retrieval components will be used, however, to adapt DPR snowfall retrievals. Furthermore, no major adjustments are made to the combined CORRA products, as these are based primarily on the DPR data.

\section{a. Classification-induced differences}

A major algorithm difference identifiable in Fig. 1 is that the DPR NS, HS, MS, and CORRA estimates (Figs. 1a,b,c,e) show significant snow over mid-highlatitude oceans (e.g., Gulf of Alaska), whereas CloudSat 2CSP and GMI GPROF do not. This is because the DPR and CORRA algorithms use precipitation phase at the lowest radar range gate uncontaminated by surface clutter, which may be $0.5-2.0 \mathrm{~km}$ above the surface (even over oceans). The profile of phase (ice, melting, or liquid) is determined via a brightband detection algorithm or, if one is not detected, the temperature profile provided by ancillary model data [JMA's Global Analysis (GANAL)]. Meanwhile, CloudSat 2CSP uses the estimated height of the melting level from the European Centre for MediumRange Weather Forecasts (ECMWF) analysis and models for expected snow particle melting to distinguish snow from rain. Since temperature typically decreases with height in the boundary layer, the lowest clutter-free range gate is likely to be systematically colder than the surface, resulting in too-frequent classification of precipitation as snowfall by the DPR and CORRA algorithms. The Tang et al. (2017) results also indicate widespread DPR surface snowfall signatures at equatorward latitudes compared to other global snowfall estimates like CloudSat 2CSP, most likely because of DPR's snow-rain classification approach. In contrast, the GPROF algorithm for GMI (and other passive microwave sensors; Kummerow et al. 2015) uses T2m from global weather model analyses to classify the probability of snow versus rain using the approach of Sims and Liu (2015). The model is GANAL for GMI GPROF near-real-time and production products while ECMWF interim reanalysis (ERA-Interim) (Dee et al. 2011) is used for the GMI GPROF CLIM (climate) products. Le et al. (2017) have introduced a different, experimental method of rain/snow classification for DPR using characteristics of the dual-frequency ratio profile, but this still only uses data above the surface clutter. Since each of the algorithms classifies surface snow differently, having a common definition of what constitutes falling snow is imperative for snow intercomparison studies.

To test the theory that a snow product difference lies in the adopted surface snow/phase identifier schemes for the various algorithms, the DPR retrievals were reclassified using the Sims and Liu (2015) probabilistic phase from the nearest GMI pixel to distinguish liquid rain from falling snow, with an upper threshold of $15 \%$ liquid required for a snow classification. While not exactly the same, this is consistent with the CloudSat 2CSP methodology, which allows snow particles to fall a distance below the melting level, as diagnosed from coincident temperature profiles, and still be considered snow. The distance is based on modeling of particle melting that shows the resulting melted mass fraction to be less than $15 \%$. The results of that test are shown in the snow frequency plots of DPR MS, DPR MS (with T2m adjustment), CPR, and GMI GPROF in Figs. 3a-d, respectively. Clearly, these DPR falling snow retrievals in the northernlatitude oceans are much closer to the GMI GPROF and CloudSat 2CSP snow products. Therefore, for consistency, the T2m adjustment for DPR snow retrievals will be used in the rest of the analyses in this paper.

We also compare the DPR V05 phaseNearSurface (PNS) flag to the experimental flagSurfaceSnowfall (FSS) flag of Le et al. (2017) and the nearest-GMIderived phase in Fig. 4. Over land, the methods result in fairly similar snow occurrences, although the PNS tends to slightly overestimate snowfall compared to the FSS flag, which in turn is a slight overestimate compared to the T2m method. Over oceans, the PNS and FSS flags are fairly similar although some regional patterns are evident: particularly, the PNS flag has a greater snowfall occurrence downwind of the continents in the Northern Hemisphere and near Antarctica, whereas FSS occurrences are slightly greater upwind of continents and in the middle latitudes $\left(40^{\circ}-50^{\circ} \mathrm{S}\right)$ of the Southern Ocean. 

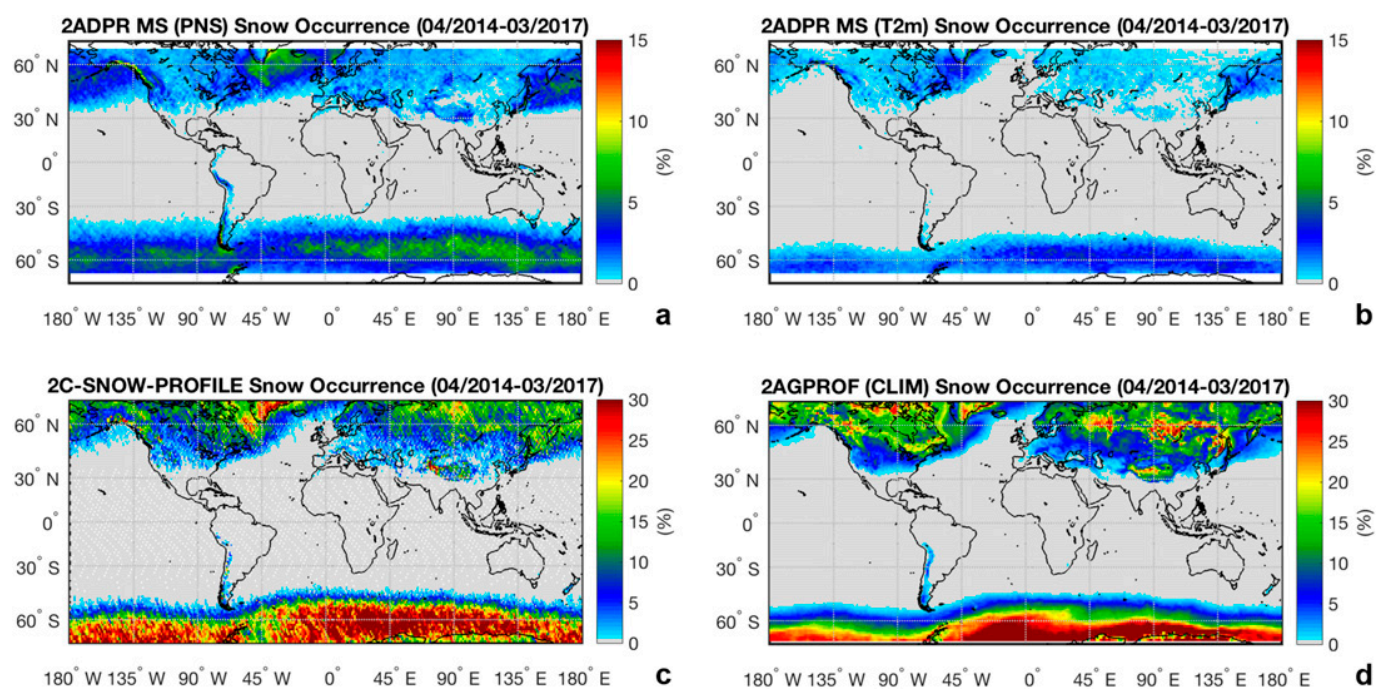

FIG. 3. Snow occurrence percentage for (a) DPR MS, (b) DPR MS with the GMI (Sims and Liu 2015) T2m snow classification methodology, (c) CloudSat 2CSP, and (d) GMI GPROF retrievals. Different scales are adopted for the top panels to accentuate regional snowfall occurrence patterns.

A far more significant reduction in snowfall occurrence is seen in Fig. 4 when the T2m method is applied. Remarkably, this method nearly entirely eliminates the occurrence of snow over the Gulf of Alaska, northern Atlantic south and east of Iceland, and Southern Ocean north of about $50^{\circ} \mathrm{S}$. The land-ocean disparities among various classification methods make sense in that cold air outbreaks over ocean produce steeper lapse rates than over land (because of the larger heat capacity of water), which coupled with the surface moisture flux are more likely to produce shallow convection (Kulie et al. 2016; Kulie and Milani 2018). Thus, over-ocean retrievals are much more susceptible than those over land because of classification errors in the radar-based methods that do not use information about the temperature structure near the surface. This does not necessarily mean that the GMI GPROF and CloudSat 2CSP approach is always better than the DPR approach since it relies upon a model analysis, which may be in error, particularly near sharp temperature gradients and complex terrain, whereas the DPR approach uses the radar measurements more directly.

\section{b. Sampling-induced differences}

Orbits, instrument resolutions, and scanning patterns introduce sampling-induced differences. The GPM Core Observatory spacecraft carrying DPR and GMI is in a non-sun-synchronous orbit with inclination angle of $65^{\circ}$ meaning that only precipitation between the latitude bands of about $\pm 70^{\circ}\left( \pm 66^{\circ}\right)$ is observed by GMI (DPR) because of the extension of their swath widths beyond the inclination latitude. The CloudSat 2CSP snow estimates go nearly pole to pole $\left( \pm 82^{\circ}\right)$, since it is at a $98^{\circ}$ inclination. Thus, CloudSat observes significant amounts of snow located near the poles that GPM misses (especially near Antarctica where light snow is more frequent). On the other hand, GPM's orbit allows for sampling the diurnal cycles that CloudSat cannot provide. The diurnal cycle in mid- and high-latitude cold season precipitation, where snow is most prevalent, is weaker than in warm season liquid precipitation (Dai 2001). GPM observations, however, indicate an early morning snowfall occurrence maximum over Northern Hemispheric oceanic regions (Adhikari et al. 2018). Possible diurnal influences are not corrected in our analyses.

In Fig. 1, it is not instantly apparent that the sampling from the different orbits and swath widths play a role in the annual snow amounts. While numerous studies have shown global snowfall using gridded CloudSat products (Liu 2008a; Kulie et al. 2016; Kulie and Milani 2018), most of these studies utilize CloudSat observations from the 2006-10 data record when the CPR operated continuously. Over most of its lifetime, CloudSat has flown in formation with NASA's A-Train, or Afternoon Constellation of satellites led by Aqua. After a battery system anomaly caused an inoperative period of several months in 2011, CloudSat began operating in a "daytime-only operations" mode. For this mode, starting in November 2011, the CPR has made measurements during only the sunlit portion of the orbit. Figure 5 illustrates the latitudinally imbalanced sampling that results for these more recent CloudSat observations. There is a clear Northern Hemispheric bias 


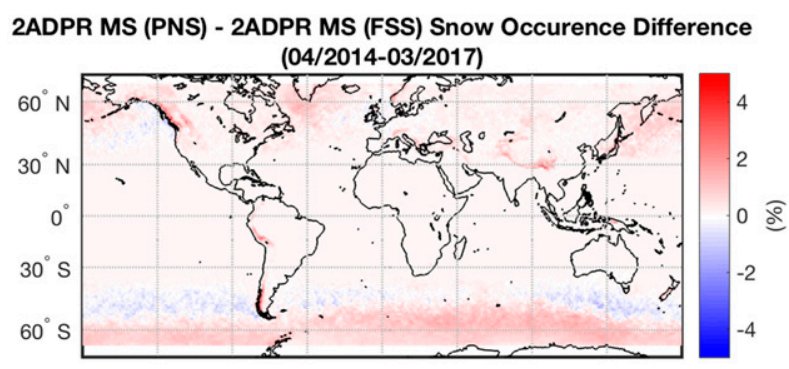

$180^{\circ} \mathrm{W} 135^{\circ} \mathrm{W} 90^{\circ} \mathrm{W} 45^{\circ} \mathrm{W} \quad 0^{\circ} \quad 45^{\circ} \mathrm{E} \quad 90^{\circ} \mathrm{E} \quad 135^{\circ} \mathrm{E} 180^{\circ} \mathrm{E} \quad \mathbf{a}$

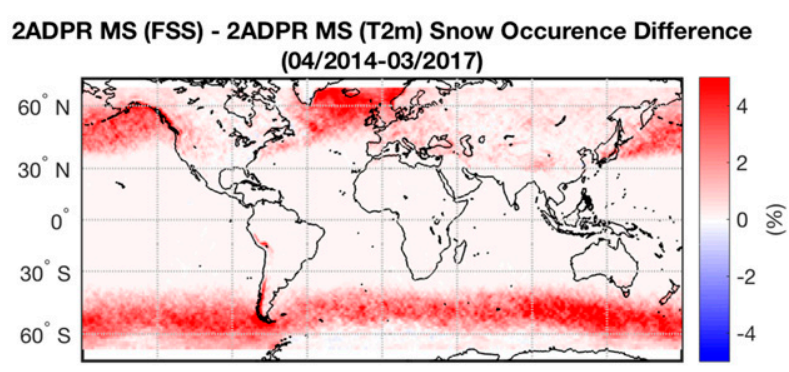

$180^{\circ} \mathrm{W} 135^{\circ} \mathrm{W} 90^{\circ} \mathrm{W} 45^{\circ} \mathrm{W} \quad 0^{\circ} 45^{\circ} \mathrm{E} \quad 90^{\circ} \mathrm{E} 135^{\circ} \mathrm{E} 180^{\circ} \mathrm{E} \quad$ b

2ADPR MS (PNS) - 2ADPR MS (T2m) Snow Occurence Difference

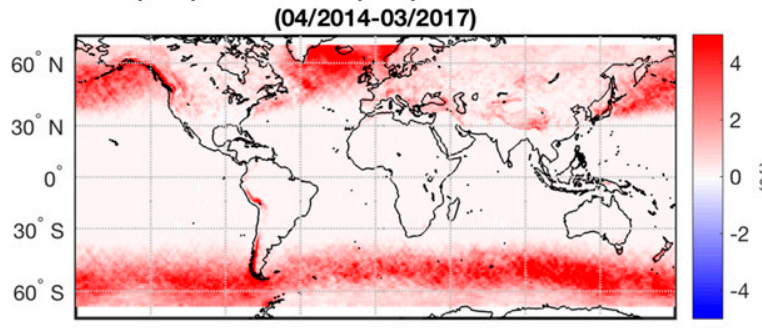

$180^{\circ} \mathrm{W} 135^{\circ} \mathrm{W} \quad 90^{\circ} \mathrm{W} \quad 45^{\circ} \mathrm{W} \quad 0^{\circ} \quad 45^{\circ} \mathrm{E} \quad 90^{\circ} \mathrm{E} \quad 135^{\circ} \mathrm{E} 180^{\circ} \mathrm{E} \quad$ C

FIG. 4. DPR MS surface snow occurrence differences using different phase classification schemes. Differences between (a) original DPR algorithm using the phaseNearSurf (PNS) and Le et al. (2017) flagSurfaceSnowfall (FSS) flags, (b) FSS and Sims and Liu (2015) T2m, and (c) PNS and T2m methodologies.

in CloudSat observations because the CPR operates during the first part of the descending orbital path [i.e., CPR takes some observations after transitioning from ascending (daylight) to descending (no daylight) orbital mode]. Depending on the season, CPR observations are reduced or nonexistent over extreme Southern Hemisphere latitudes because of limited solar input for power and a slight lag when the CPR is powered on during the descending to ascending orbital transition. CPR observations are restricted to GPM latitudinal limits in this study, thus reducing the number of Southern Hemisphere CPR data void regions in the complete dataset. Some seasonal CPR data gaps may still exist in the extreme southern portions of GPM's latitudinal range during austral winter.

To derive meaningful and comparable near-global snowfall rates and occurrences from CPR and DPR,

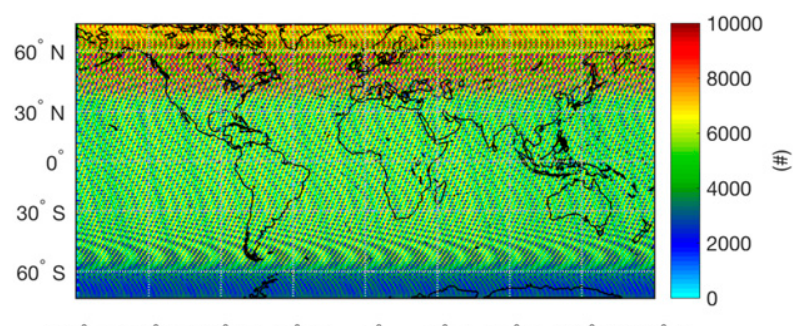

$180^{\circ} \mathrm{W} 135^{\circ} \mathrm{W} 90^{\circ} \mathrm{W} 45^{\circ} \mathrm{W} \quad 0^{\circ} \quad 45^{\circ} \mathrm{E} \quad 90^{\circ} \mathrm{E} 135^{\circ} \mathrm{E} 180^{\circ} \mathrm{E}$

FIG. 5. CloudSat orbits for the April 2014-March 2017 period. Hemispheric differences are due to CloudSat "daylight-only" operations after November 2011. The Northern Hemisphere contains more orbits since the CPR operates during a portion of the descending orbital path during both austral and boreal summers.

only CPR observations within $\pm 66^{\circ}$ are considered in this analysis. The mean snowfall rate and snowfall occurrence were calculated in $1^{\circ}$-latitude bands and weighted by the cosine of latitude, and the weighted means are given in Table 3. Only the near-nadir DPR data were considered in order to mimic as closely as possible the CPR lowest clutter-free bin height. Clearly, CPR's superior detection is evident in that it observes an order of magnitude more snowfall occurrence than DPR; however, because these are light events below the detection thresholds of DPR, in terms of rate the CPR: DPR ratio is only a factor of 3 . There are also some differences between the DPR products. While the DPR NS and DPR MS retrievals are nearly identical, the DPR HS retrieval only detects $76 \%$ of the snow occurrence of the DPR NS, (and DPR MS) retrievals, and $50 \%$ of the snowfall rate. While it is not surprising that the DPR NS and DPR MS statistics are similar (the Ku MDR is much lower than the Ka MS MDR, and both are used in the MS algorithm), it is somewhat surprising that the DPR HS detection is lower than DPR NS, since the DPR HS MDR is similar to DPR NS (Toyoshima et al. 2015).

TABLE 3. Global snowfall occurrence (between $\pm 66^{\circ}$ ) and mean rate from CloudSat 2CSP and DPR products. Only the near-nadir DPR profiles (rays 23-25, 11-13, and 11-12 for NS, MS, and HS, respectively) were considered in order to minimize height of the lowest clutter-free bin above the surface, and the phase classification was matched to the nearest GMI GPROF pixel.

\begin{tabular}{lcc}
\hline \hline \multicolumn{1}{c}{ Instrument } & $\begin{array}{c}\text { Snow } \\
\text { occurrence }(\%)\end{array}$ & $\begin{array}{c}\text { Mean snow rate: } \\
\mathrm{mm} \mathrm{day}^{-1}\left(\mathrm{~mm} \mathrm{yr}^{-1}\right)\end{array}$ \\
$\begin{array}{l}\text { CloudSat (native } \\
\text { resolution) 2CSP }\end{array}$ & 2.422 & $0.1229(44.9)$ \\
DPR NS & 0.262 & $0.0401(14.6)$ \\
DPR MS & 0.262 & $0.0402(14.7)$ \\
DPR HS & 0.199 & $0.0208(7.60)$ \\
CMB NS & 0.284 & $0.0414(15.1)$ \\
CMB MS & 0.284 & $0.0444(16.2)$ \\
\hline
\end{tabular}


TABLE 4. CloudSat 2CSP snowfall occurrence and global mean snowfall rate after performing along-track averaging and truncation to match DPR instrument characteristics.

\begin{tabular}{lcccc}
\hline \hline & \multicolumn{2}{c}{$\begin{array}{c}\text { Snow } \\
\text { occurrence }(\%)\end{array}$} & \multicolumn{2}{c}{$\begin{array}{c}\text { Mean snow rate } \\
\left(\mathrm{mm} \mathrm{day}^{-1}\right)\end{array}$} \\
\hline $\begin{array}{l}\text { 2CSP along-track } \\
\quad \text { averaging }\end{array}$ & All data & $>8 \mathrm{dBZ}$ & All data & $>8 \mathrm{dBZ}$ \\
5 pixel & 2.879 & 0.277 & 0.1212 & 0.0613 \\
11 pixel & 3.303 & 0.277 & 0.1212 & 0.0575 \\
\hline
\end{tabular}

For occurrence statistics, the different sizes of the CPR and DPR footprints must also be considered. The area of a DPR footprint is about 11 times larger than a CPR footprint. However, because precipitation is not randomly distributed within a DPR footprint and CPR only samples along-track, an 11-footprint moving average of CloudSat 2CSP may not result in equivalent sampling statistics to DPR, so in Table 4, 5- and 11footprint moving averages are used to calculate snow occurrence and mean rate using all data, to give reasonable bounds on the conversion of 1-D CloudSat 2CSP to two-dimensional (2D) DPR statistics. As expected, the mean rate is unaffected, but the occurrence increases from $2.4 \%$ (native) to $2.9 \%$ and $3.5 \%$ for the 5- and 11-pixel moving averages (somewhat similar to Behrangi et al. 2012), respectively, further exacerbating the discrepancy with DPR due to sensitivity differences.

\section{c. Instrumentation-induced differences}

The differences caused by instrumentation fall into 1) detectability/sensitivity thresholds, 2) differences in backscattering efficiency of various snowflake shapes/sizes at each frequency, and 3) surface clutter. These differences are not easily mitigated because they are inherent properties of the instrumentation design; however, some techniques can be used to equalize comparisons. With regard to differences in backscattering efficiency, the scattering model handles these-this is just a way of stating that even if a Ku-band and W-band radar had the same sensitivity (e.g., $0 \mathrm{dBZ}$ ), they would still see different snowfall occurrence because of these backscattering differences. Surface clutter is a more fundamental problem that cannot be easily fixed, but using near-nadir DPR pixels, such as for the MS products, and CPR nadir-beam observations allow for both instruments to experience about the same amount of surface clutter.

As Table 1 states, Fig. 2 shows, and section 2 discusses, CPR has a much lower MDR. This increased sensitivity allows CPR to observe smaller snow rates than GPM's DPR. It is not possible to increase DPR's sensitivity to small snowfall rates postlaunch, but it is possible to artificially truncate CPR's MDR. This synthetic CPR MDR application allows for global snowfall comparisons between CPR and DPR at a common detectable range of snow rates; it does not however, allow one to compute total snow accumulations globally. Because the same snow PSD may produce markedly different reflectivity at $\mathrm{Ku}, \mathrm{Ka}$, and $\mathrm{W}$ band (Kneifel et al. 2011; Leinonen et al. 2012; Kulie et al. 2014), there is not a one-to-one relationship between the DPR MDR and an equivalent $\mathrm{W}$-band threshold. However, a statistical threshold may be derived by truncating the CPR observations at progressively higher thresholds of reflectivity until the near-global snowfall occurrence is reduced to the DPR level. This approach is illustrated in Fig. 6 where the truncated CloudSat 2CSP occurrence and rate cumulative distribution functions (CDF) are compared to the DPR MS CDFs. Using this approach, a lower sensitivity cutoff for CPR of $8-9 \mathrm{~dB} Z$ yields the same global snowfall occurrence as detected by DPR MS (the exact value depends on whether attenuationcorrected or observed W-band reflectivities are used and the length of the along-track averaging window applied to the CloudSat data). While this is lower than the DPR minimum sensitivity of about $13 \mathrm{dBZ}$ at $\mathrm{Ku}$ band, it is consistent with the frequency-dependent backscattering efficiency reduction that is observed and produced by scattering models (Liu 2008b; Tyynela et al. 2011; Kuo et al. 2016). The 8-dBZ CPR cutoff produces the same approximate number of global snowfall occurrences as DPR (Fig. 6), while regional snowfall occurrence differences remain between the DPR MS and truncated CloudSat 2CSP snowfall datasets (Fig. 7). Even after applying a synthetic 8-dBZ MDR, CloudSat 2CSP observes more snow occurrences (Fig. 7a) and higher annual mean snowfall rate (Fig. 7b) than DPR MS over many mountainous regions (e.g., Greenland, the Himalayas, Alaskan and western Canadian mountains, Andes Mountains, coastal Norway) and large portions of the Southern Ocean. Conversely, DPR MS indicated snow occurrences exceed CloudSat 2CSP in some Northern Hemispheric oceanic (e.g., east of Asia and North America) and continental (e.g., eastern half of Canada, western Russia) regions. These inflated DPR MS snowfall occurrences, however, do not produce drastically different mean annual snowfall rate differences (Fig. 7b). These regional differences can be partially explained by possible snowflake microphysical details. For instance, if the truncated 8-dBZ CloudSat 2CSP dataset detects more snowfall than DPR MS in a given region, it implies that $\mathrm{Ku}-\mathrm{W}$ differences are less than average, and, therefore, snow PSDs consist of smaller particles on average in that region. Conversely, 
(a)

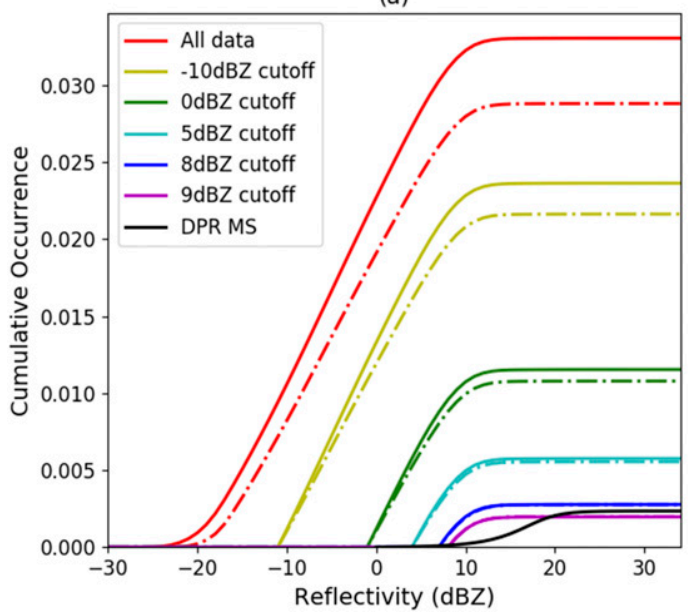

(b)

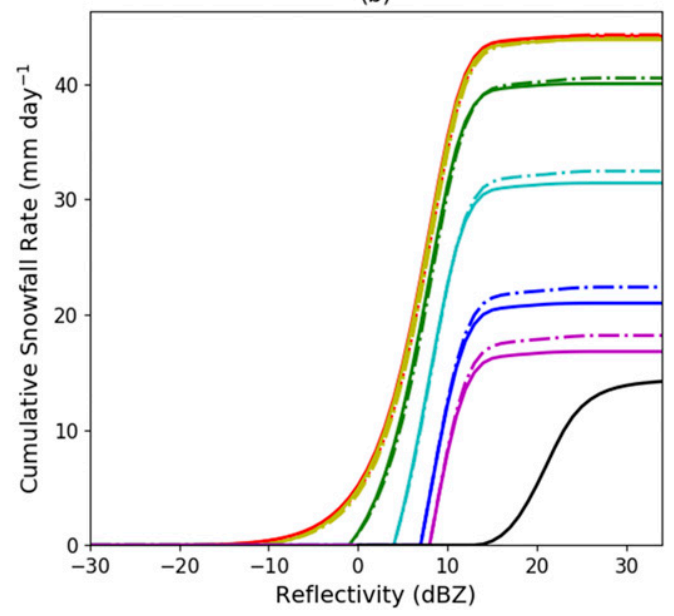

FIG. 6. Cumulative probability distribution plots with respect to reflectivity for various CloudSat along-track averaging (solid: 11 pixel; dot-dash: 5 pixel) and minimum reflectivity cutoffs as compared to DPR MS (using the $\mathrm{Ku}$-band reflectivity and with $\mathrm{T} 2 \mathrm{~m}$ snow classification applied): (a) cumulative occurrence and (b) cumulative snowfall rate.

where the CloudSat 2CSP (8-dBZ cutoff) dataset detects less than DPR in certain regions, it would imply that $\mathrm{Ku}-\mathrm{W}$ differences are greater than average, which can be interpreted as the influence of larger particles.

Despite yielding a similar occurrence, Table 4 shows that a cutoff of $8 \mathrm{dBZ}$ for CloudSat 2CSP yields a mean snowfall rate $43 \%$ higher than DPR MS and $30 \%$ higher than CMB MS. This points to further differences in the algorithm related to the snow microphysical assumptions and scattering models that lead to higher snowfall rates from CloudSat 2CSP than DPR, even when the same events are being observed. In section 4 , we will attempt to reconcile this discrepancy using common scattering models and PSD assumptions.

\section{d. Summary of classification, sampling, and instrumentation adjustments}

Comparisons between GPM and CloudSat products are more equitable after adjusting for classification [using a common $\mathrm{T} 2 \mathrm{~m}$ approach as specified by Sims and Liu (2015)]. The adjustment for sampling by averaging over $11 \mathrm{CPR}$ pixels over similar latitude and longitude ranges also reduces differences. Using a CPR cutoff of $8-9 \mathrm{dBZ}$ puts the occurrence statistics of falling snow from CloudSat 2CSP and DPR on equal grounds. However, Table 4 shows that even with all these adjustments implemented as described in section 3, the average falling snow rates of CloudSat 2CSP far exceed those of the DPR. These differences in average falling snow rates seem inconsistent with the reflectivity ranges shown in Fig. 2. This inconsistency is likely symptomatic of differences in the fundamental underlying assumptions (e.g., microphysical and scattering properties) made by the DPR- and CPR-based retrieval algorithms. These assumptions affect the implicit relationships between snowfall rate and radar reflectivity at the core of these algorithms. By applying a consistent

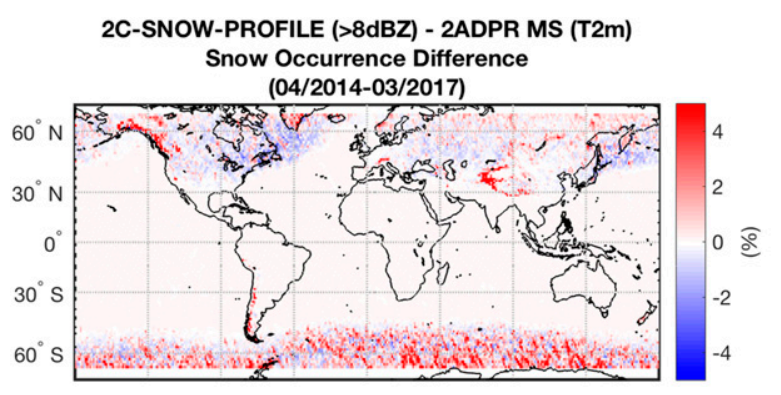

$180^{\circ} \mathrm{W} 135^{\circ} \mathrm{W} 90^{\circ} \mathrm{W} \quad 45^{\circ} \mathrm{W} \quad 0^{\circ} \quad 45^{\circ} \mathrm{E} \quad 90^{\circ} \mathrm{E} \quad 135^{\circ} \mathrm{E} 180^{\circ} \mathrm{E} \quad \mathbf{a}$

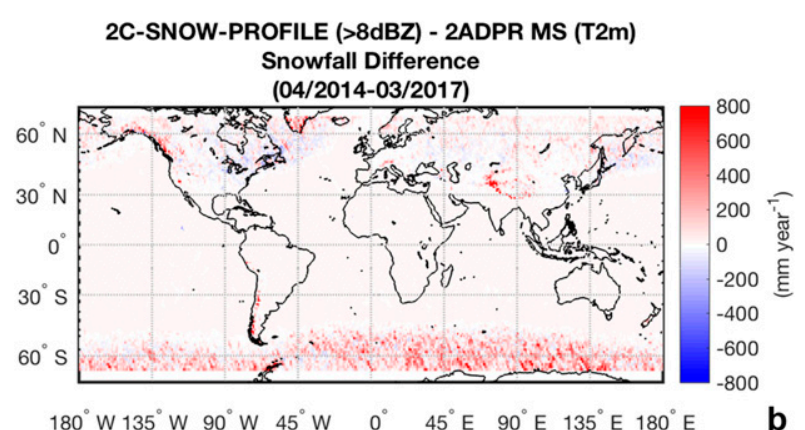

FIG. 7. CloudSat 2CSP (8-dBZ threshold applied) and DPR MS (2-m wet-bulb temperature surface phase classifier applied) differences for (a) snow occurrence (\%) and (b) mean annual snowfall rate $\left(\mathrm{mm} \mathrm{yr}^{-1}\right)$. 
explicit $Z-S$ relationship to observed reflectivities, this inconsistency can be minimized, allowing the adequacy of the mitigations described in section 3 to be examined. Demonstrating that these mitigations are adequate provides justification for their use to establish equitable bases for comparisons of CloudSat, DPR, and other future falling snow retrieval products.

\section{Algorithm $(Z-S)$ differences}

As shown in section 3 and Table 4, even when accounting for differences in classification, footprint size, and sensitivity, there remains a residual difference of $30 \%-40 \%$ in global mean snowfall rate between the CloudSat and DPR estimates. Since the radar algorithms require assumptions about the snow microphysical properties and scattering models to relate observed reflectivity to estimated snowfall rate, in this section we will develop and apply a consistent set of $Z-S$ relationships at $\mathrm{Ku}$ and $\mathrm{W}$ band to the respective DPR and CPR observed reflectivity probability distribution functions (PDF) in order to determine if these result in a more consistent snowfall rate PDF and globally averaged snowfall rate. It is important to note that these are not meant to replace the existing official falling snow products. W-band reflectivities observed from satellite, in particular, can be subject to hydrometeor attenuation that may be balanced partially by multiple scattering effects (e.g., Matrosov and Battaglia 2009) and this can lead to saturation of W-band reflectivity (Matrosov 2019). Performing retrievals in profile (e.g., Wood and L'Ecuyer 2013), as opposed to applying $Z-S$ relationships to individual radar bins, and using a reflectivity forward model that models attenuation and multiple scattering effects can compensate to some extent for these effects. In this work, however, the $Z-S$ relationships are applied to $\mathrm{W}$-band reflectivities that have been corrected for estimated path integrated attenuation where possible (Haynes et al. 2009). Further, the focus of this work is not to develop and provide approximate, numerical $Z-S$ relationships as could be used to develop a retrieval product. Instead, these fitted relationships serve only as a tool by which the reflectivities as observed by the different instruments can be compared on a common basis (i.e., as snowfall rates) of meteorological and hydrological relevance.

To begin, we derived a table relating snow water content, snowfall rate, and reflectivity at $\mathrm{Ku}, \mathrm{Ka}$, and $\mathrm{W}$ bands using an exponential PSD with constant intercept parameter $\left(N_{o}=10^{5} \mathrm{~m}^{-4}\right)$. The exponential slope parameter was varied to produce an array of PSDs with mean mass-weighted diameter $D_{m}$ increasing from 0.28 to $12 \mathrm{~mm}$. Snowfall rates for the respective PSDs were calculated using aggregate snowflake mass and particle fall speed relationships derived from previous studies (e.g., Locatelli and Hobbs 1974; Mitchell 1996; Wilson and Ballard 1999; Heymsfield et al. 2004). The best fit microphysical relationships adopted for this study are shown in online supplemental Fig. S1. Simulated multifrequency radar reflectivities were produced by integrating modeled snowflake backscattering properties over the PSDs [e.g., Wood et al. 2015, their Eq. (15)]. An ensemble of aggregate snowflake models from the Kuo et al. (2016) database (maximum particle size exceeded $25 \mathrm{~mm}$ ) was used to calculate mean snowflake backscattering properties. Scattering models from the Liu (2008b) database were also used to augment the ensemble snowflake backscattering database at particle sizes smaller than $1 \mathrm{~mm}$. Ensemble mean particle backscatter cross sections for the three radar frequencies of interest are shown in supplemental Fig. S2. The maximum simulated $\mathrm{Ku}-\mathrm{Ka}(\mathrm{Ku}-\mathrm{W})$ dual-frequency ratio was $\sim 10(\sim 17) \mathrm{dB}$ using the described scattering model and PSD combinations (supplemental Fig. S3). A table showing the snowfall rate and reflectivity calculations are also provided as supplemental material (Table S1). Combining simulated snowflake scattering properties with various PSD and mass/fall speed assumptions in a similar fashion as the current study has been adopted in previous studies for different snowfall remote sensing applications (e.g., Liu 2008a; Kulie and Bennartz 2009; Kulie et al. 2010; Kneifel et al. 2011, 2015; Leinonen and Moisseev 2015; Olson et al. 2016).

We then used the $\mathrm{Ku}-\mathrm{Ka}$ dual-frequency ratio from two radar datasets to derive $D_{m}$ given the PSD and scattering assumptions described above as demonstrated by Liao et al. (2016). The first dataset is the matched $\mathrm{Ku}-\mathrm{Ka}$-band near-surface reflectivities from DPR, filtered by the GMI GPROF precipitation type as described in section 3a. To achieve better sensitivity at $\mathrm{Ka}$ band than is available from the MS (matched scan) data, the HS (high sensitivity) data at Ka were used, which are interleaved between the Ku scans (Toyoshima et al. 2015) and have a 500-m vertical range gate. For each $\mathrm{Ka}$ data point the surrounding $4 \mathrm{Ku}$ rays at the two corresponding $\mathrm{Ku}$ range gates (for a total of $8 \mathrm{Ku}$ reflectivity measurements) were averaged (after converting to linear $Z$ units of $\mathrm{mm}^{6} \mathrm{~m}^{-3}$ ) to get a matched $\mathrm{Ku}$ and Ka reflectivity pair. The second dataset was derived from the Airborne Precipitation Radar-2 (APR-2) measurements during the GPM Cold-Season Precipitation Experiment (GCPEx; Skofronick-Jackson et al. 2015). Six cases with snow as the predominant precipitation type were selected (Table 5) representing synoptic and lakeeffect snow events. Only observations within $1 \mathrm{~km}$ of 

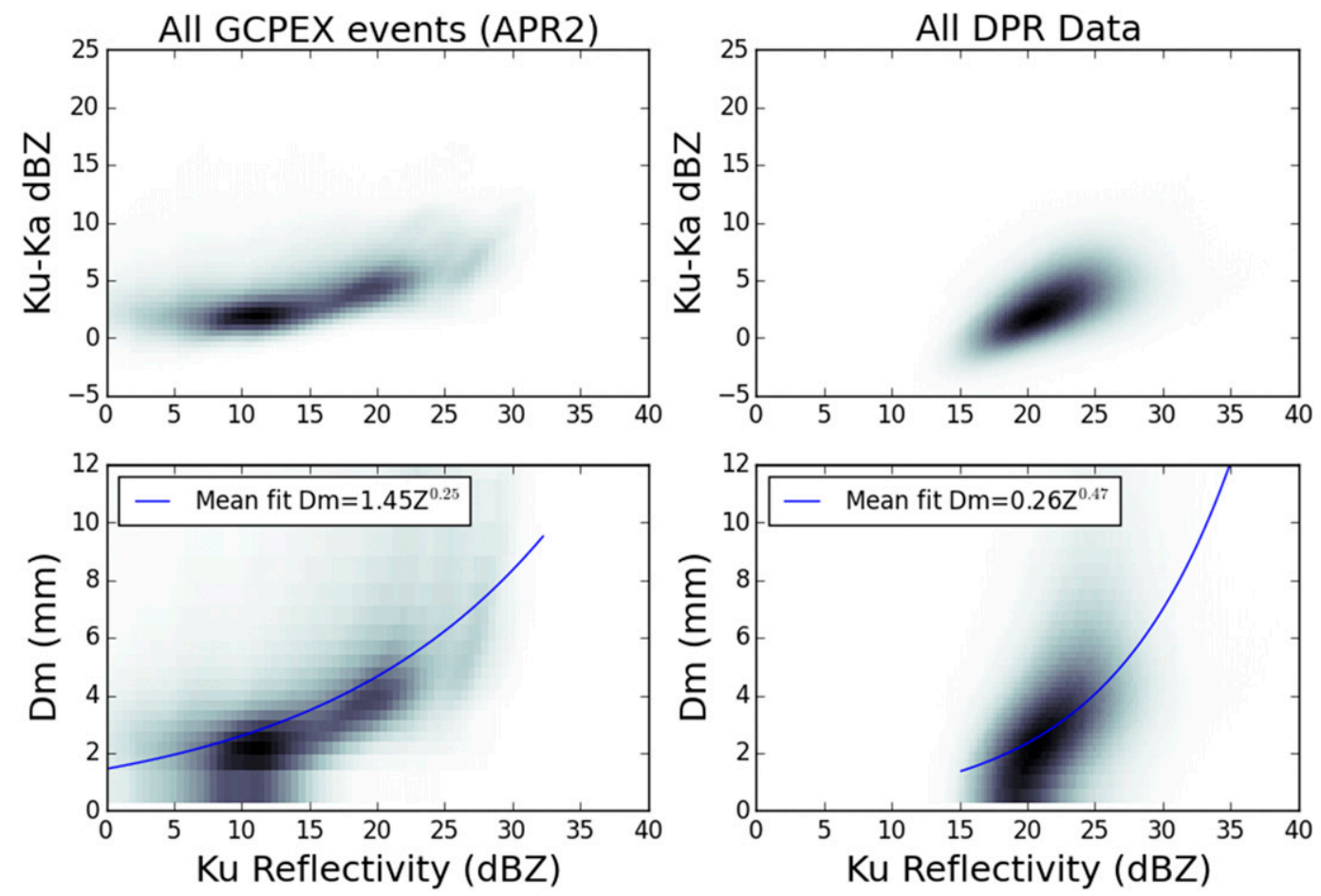

FIG. 8. Two-dimensional normalized histograms of $\mathrm{Ku}$ and Ka reflectivity measured by APR2 during (top left) GCPEx and (top right) DPR. (bottom) The $y$ axis has been converted to units of mean mass-weighted particle size and a power law, with coefficients given in the legend, has been fit to the mean values at each $\mathrm{Ku}$-band reflectivity bin.

the ground were considered in order to represent nearsurface microphysics. Although the APR-2 dataset is not nearly as broad as the DPR dataset, the APR-2 sensitivity is superior to DPR with a Ku-band sensitivity near $0 \mathrm{dBZ}$ and Ka-band sensitivity near $-20 \mathrm{dBZ}$ during GCPEx (Durden et al. 2012). These are useful for developing $Z-D_{m}$ relationships that can be applied to CPR reflectivities far below the DPR minimum sensitivity.

The two-dimensional histograms of $\mathrm{Ku}$ and $\mathrm{Ka}$ reflectivity from APR-2 and DPR are shown in the top panels of Fig. 8. In the bottom panels, the PDFs are shown with the $y$ axis converted to $D_{m}$ using the tables derived previously. Both the APR-2 and DPR data show a clear trend toward increasing $\mathrm{Ku}-\mathrm{Ka}$ difference (and therefore, increasing $D_{m}$ ) as $\mathrm{Ku}$ reflectivity increases. The mean DFR-derived $D_{m}$ in each $0.25-\mathrm{dB} Z_{\mathrm{Ku}}$ bin was used to fit a least squares $Z_{\mathrm{Ku}}-D_{m}$ power law, weighted by the total number of observations in each $0.25-\mathrm{dB} Z_{\mathrm{Ku}}$ bin. The coefficients of these power laws (fitted with $Z$ in linear, not $\log$, units) are given in the Fig. 8 legends. The $Z_{\mathrm{Ku}}-D_{m}$ power law fit to the APR-2 data has a larger intercept and lower exponent than the DPR fit, resulting in larger $D_{m}$ values up to a $\mathrm{Ku}$ reflectivity of about $33 \mathrm{~dB} Z$. This difference could be a result of the presence of supercooled water in lake-effect snow, which is likely overrepresented in the APR-2 sample and can enhance the dual-frequency ratio at low altitudes because of attenuation. This enhancement, if interpreted as $D_{m}$, would erroneously result in larger than actual $D_{m}$ values. Notwithstanding this potential source of error, we will take the APR-2 and DPR $Z-D_{m}$ fits to establish upper and lower bound $Z-S$ lookup tables at $\mathrm{W}$ band, using the same self-consistent table of $Z, D_{m}$, and $S$.

Applying these $Z-S$ tables to the observed $\mathrm{Ku}-$ and W-band reflectivity PDFs from DPR and CPR, respectively, results in the snowfall rate PDFs shown in Fig. 9. The APR-2 fit, when applied to the CPR reflectivity PDF, results in much higher snowfall amount at all rates compared to when it is applied to the DPR data. However, the DPR-based fit gives similar results when applied to both reflectivity PDFs, when only the range above the DPR sensitivity (about $0.2 \mathrm{~mm} \mathrm{~h}^{-1}$ with this fit) is considered. The resulting near-global snowfall rates are given in Table 6, where it is evident that the DPR-based fit snowfall rate distribution provides a closer match than the APR2-based fit. The DPR NS $\left(0.0467 \mathrm{~mm} \mathrm{day}^{-1}\right)$ and truncated CPR $\left(0.0392 \mathrm{~mm} \mathrm{day}^{-1}\right)$ global mean snowfall rate relatively differ by $\sim 16 \%$ using the DPR-based fit. This relative difference increases to 

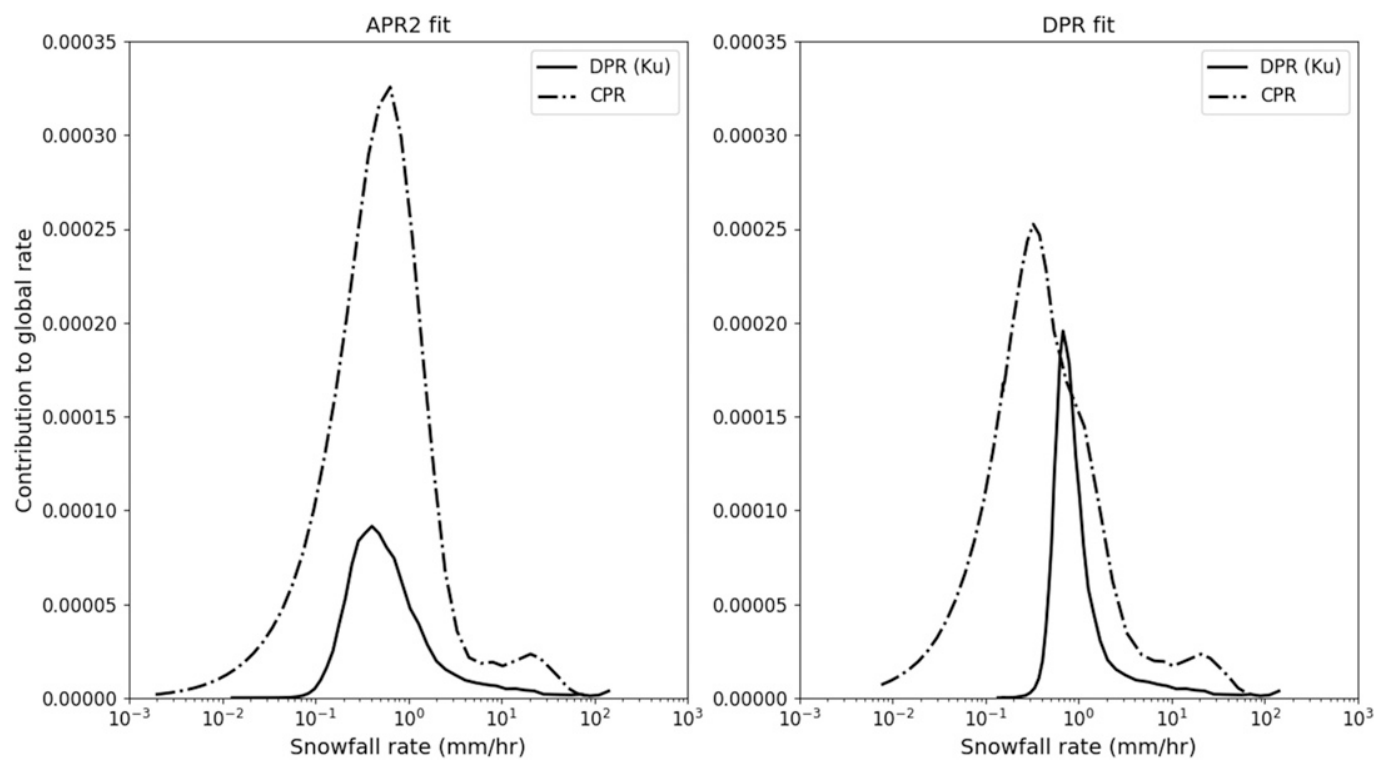

FIG. 9. Near-global snowfall PDF derived from DPR- and CPR-observed reflectivity PDFs. (left) $Z-S$ relationships derived from APR2 data during GCPEx and (right) data derived from DPR.

$\sim 60 \%$ using the APR2-based fit, with CPR conversely displaying a larger mean snowfall rate compared to the DPR-based fit. Caution should be used when interpreting these results because of the respective dataset discrepancies, especially at lower CPR reflectivities where there is little information from the $\mathrm{Ku}-$ Ka measurements to derive $Z-S$ relationships. These results, however, show that the large DPR-CPR global snowfall rate differences using native datasets (CPR exceeded DPR by a factor of 3) can be reduced to under $20 \%$ by systematically eliminating dataset differences caused by algorithm assumptions (PSD assumptions, size-fall speed relationships, phase classification schemes), and inherent instrument discrepancies as noted in section 3. As the size-fall speed relationship used to derive this snowfall rate is another source of uncertainty, it should be recognized that the value of the calculated global mean snowfall rate is less meaningful than the finding that when the CPR and DPR reflectivity PDFs are analyzed on a common basis, the calculated global mean rates are consistent with each other. Another significant finding is that the range of snowfall rates for which Ka band offers independent information to $\mathrm{Ku}$ band can be gleaned from Fig. 8. Both APR-2 and DPR datasets show that the $\mathrm{Ku}-\mathrm{Ka}$ difference begins to significantly depart from $0 \mathrm{~dB}$ around $\mathrm{Ku}$ reflectivity values of $15 \mathrm{dBZ}$. Coincidentally, this is close to DPR's minimum detectable reflectivity, and suggests that over nearly the entire range of snowfall rates DPR can detect, which by our methodology accounts for nearly $50 \%$ of global snowfall by amount, the Ka band provides additional information to constrain the snowfall rate. In May 2018 the DPR scan pattern was changed to collocate the HS Ka footprints to match the outer swath of the $\mathrm{Ku}$ footprints (Iguchi et al. 2018) and this should provide a better constraint on the snow PSDs at low reflectivities than the MS products used herein that lose the Ka signal at $18 \mathrm{dBZ}$.

\section{Discussion and conclusions}

GPM, version 05, snowfall estimates are now available from DPR, GMI, and combined radar-radiometer

TABLE 5. GCPEx cases.

\begin{tabular}{lclr}
\hline \hline \multicolumn{1}{c}{ Date(s) } & Start/end time (UTC) & Type of snow & No. of DPR Ku-Ka pairs \\
\hline 19 Jan 2012 & $1507-1808$ & Synoptic & 1400707 \\
28 Jan 2012 & $1602-1916$ & Synoptic & 4853792 \\
30-31 Jan 2012 & $2338-0244$ & Synoptic with mesoscale bands & 2328110 \\
12 Feb 2012 & $0303-0624$ & Lake effect & 1398400 \\
21 Feb 2012 & $2012-2059$ & Synoptic & 992614 \\
24 Feb 2012 & $1334-1708$ & Synoptic & 2137809 \\
\hline
\end{tabular}


TABLE 6. CloudSat CPR and DPR-derived global mean snowfall rate using $Z-S$ relationships derived from APR2 and DPR data.

\begin{tabular}{lcc}
\hline Instrument & $\begin{array}{c}\text { Mean snow } \\
\text { rate }\left(\mathrm{mm} \mathrm{day}^{-1}\right) \\
\text { using APR2 fit }\end{array}$ & $\begin{array}{c}\text { Mean snow } \\
\text { rate }\left(\mathrm{mm} \mathrm{day}^{-1}\right) \\
\text { using DPR fit }\end{array}$ \\
\hline DPR $(\mathrm{Ku})$ & 0.0244 & 0.0467 \\
CPR (all data) & 0.0789 & 0.0989 \\
CPR $(>8 \mathrm{dBZ})$ & 0.0498 & 0.0392 \\
\hline
\end{tabular}

algorithm products. GPM and CloudSat global snowfall comparisons represent a natural investigative pathway, as CloudSat is an available spaceborne dataset with demonstrated global snowfall detection and retrieval capabilities; however, numerous instrument-, sampling-, and algorithm-related issues must be considered carefully, since they complicate comparisons between the respective snowfall datasets. This study characterizes some of these GPM and CloudSat snow retrieval complexities, describes best practices to adopt for comparisons, and presents a unified approach to evaluate these two spaceborne global snowfall datasets that minimizes instrument and algorithm differences.

This study highlights four instrument and algorithm related issues:

1) Surface precipitation phase classification algorithm. Adopting common phase classification parameters is essential for dataset comparisons. DPR snowfall detection results are substantially altered and much more consistent with GMI and CPR results when a GMI-like surface precipitation phase classification scheme is adopted.

2) Instrument sampling. CPR products are constrained by GPM orbital limits and are averaged over varying footprint sizes to mimic DPR-like sampling. CPR sampling deficiencies in the Southern Hemisphere are noted during the 2014-17 period.

3) Instrument sensitivity. CPR observations are artificially truncated using an 8-dBZ threshold to replicate DPR radar sensitivities. The $8-\mathrm{dB} Z$ threshold is chosen by equalizing total global snowfall occurrences from each dataset and is further justified by $\mathrm{Ku}-/ \mathrm{W}$-band reflectivity differences produced by differential particle backscattering at each radar frequency.

4) Quantitative precipitation estimate algorithm components. Consistent multifrequency reflectivity $(Z)$ to snowfall rate $(S)$ tables are created and applied directly to both radar datasets in order to mitigate algorithm assumption effects.
Equitable GPM DPR and CloudSat CPR global snowfall comparisons are enabled by considering these important issues.

This study first compares native DPR, GMI, and CPR gridded global snowfall products for the April 2014March 2017 time period. Large regional annual snowfall amount differences are produced by these disparate datasets. These results are not surprising given differing instrument characteristics and algorithm formulations employed by the various products. Native-resolution DPR and CPR radar reflectivity distributions emphasize radar sensitivity differences that allow CPR to detect lighter and more snowfall events compared to DPR. Conversely, the DPR snowfall dataset extends to larger radar reflectivities than does the CPR dataset. This difference, rooted in underlying differences in scattering and hydrometeor attenuation between DPR's Ku band and CPR's W band, proves the capability of the DPR to effectively quantify snowfall in deeper, more intense snowfall events that would likely prove difficult for the CPR. Even with DPR-like latitudinal restrictions applied, native-resolution CPR detects $\sim 9-12$ times more snowfall events than the various DPR products. Furthermore, CPR quantitatively estimates more global snow than DPR by a factor of 3. CPR observations in the CloudSat daylight operations era (after November 2011), however, are more plentiful in the Northern versus Southern Hemisphere, and thus sampling complications may arise if extreme Southern Hemisphere CPR observations are used. Larger footprint averaging (5 and 11 pixels) increases CPR snowfall event detection from $\sim 2.4 \%$ to $2.9 \%-3.5 \%$ but does not change mean snowfall rate calculations appreciably. These results confirm that native DPR and CPR observations behave consistently with inherent radar capabilities, similar to previous studies that adopt a combined DPR + CPR falling snow observational strategy (Casella et al. 2017; Adhikari et al. 2018).

Investigators using spaceborne datasets, however, must carefully consider algorithm components when analyzing surface snow retrievals. For instance, native DPR product snowfall maps indicate a much broader snowfall latitudinal range compared to GMI and CPR products (e.g., distinctive snow signals over the Gulf of Alaska, North Atlantic Ocean southern latitudes, and Southern Ocean northern latitudes). These systematic differences are caused primarily by algorithm phase classification differences, whereby version 05 DPR products use conditions at the lowest usable clutter-free data bin height to classify precipitation phase rather than attempting to assign a surface precipitation phase by other means. Adopting a 2-m wet-bulb temperature (T2m) surface 
precipitation phase classification methodology (Sims and Liu 2015) in DPR products eliminates these large surface snowfall signatures over midlatitude oceans. The $\mathrm{T} 2 \mathrm{~m}$ phase discriminant scheme provides DPR snowfall detection results that are much more consistent with GMI and CPR and indicates that underlying algorithm mechanics can drive important snowfall dataset differences. Since the hydrologic research community is a potential end user for spaceborne snowfall estimates, algorithm developers are also encouraged to provide best estimates of surface precipitation within a consistently defined, physically realistic framework. This issue is extremely challenging since quantitative spaceborne radar snowfall estimates originate from a near-surface bin at heights ranging from 0.5 to over $2 \mathrm{~km}$ to avoid surface ground clutter in lowest range gates. Future spaceborne snow remote sensing efforts should recognize the need to obtain meteorological data as near to the surface as possible to optimize surface snowfall estimates. Long-term ground-based profiling radar datasets offer the ability to investigate current and future instrument performance trade-offs to quantitatively assess near-surface bin selection criteria (e.g., Maahn et al. 2014) and meteorological conditions associated with surface snowfall.

Further steps are taken in this study to minimize DPR and CPR instruments differences, thus providing a more equitable comparison between the respective snowfall datasets. A synthetic 8 - $\mathrm{dB} Z$ minimum detectable reflectivity (MDR) is applied to the CPR dataset to mimic the DPR MDR. This artificial CPR MDR is justified by approximately equalizing snowfall occurrence statistics between the CPR and DPR snowfall populations within the same latitudinal boundaries. The $\mathrm{W}$-band 8 - $\mathrm{dB} Z$ value is also consistent with particle scattering theory that predicts $\mathrm{W}$ - and Ku-band reflectivity disparities due to backscattering efficiency differences. Despite similar snowfall populations using the $8-\mathrm{dB} Z$ CPR cutoff, CPR mean near-global snowfall rate estimates exceed DPR by $30 \%-45 \%$, although regional differences are evident, including some regions where DPR estimates more snowfall than CPR. These regional occurrence differences show regional characteristics of snow PSDs that cause the $\mathrm{Ku}-\mathrm{W}$ reflectivity to differ from the global mean, while the $30 \%-45 \%$ residual difference in global mean snowfall rate points to different algorithm assumptions.

Recognizing that the respective snowfall rate algorithms employ unique methodologies to convert radar reflectivities $(Z)$ into snowfall rates $(S)$, this study creates unified $Z-S$ tables applied to DPR and CPR observations. The unified $Z-S$ approach also allows the efficacy of the mitigations described in section 3 to be quantified. This pathway also demonstrates that future researchers can use similar mitigations to obtain an equitable basis for evaluating different algorithms against CloudSat or DPR. The $Z-S$ tables are developed using modeled aggregate snowflake scattering properties integrated over exponential particle size distributions, consistently accounting for radar wavelength differences. This final sensitivity test demonstrates that the initially large DPR-CPR global snowfall rate differences using native datasets (CPR exceeded DPR by a factor of 3 ) can be reduced to under $20 \%$ by removing dataset differences caused by differences in phase classification, sampling, instrument capabilities, and retrieval assumptions. It also points that investigators must be careful when reporting conclusions about global snowfall rates using combined spaceborne radar datasets without mitigating the quantitative snowfall estimate methodologies to establish such an equitable basis. For future studies evaluating snowfall estimates from space-based radar observations at different frequencies, multifrequency $Z-S$ tables based on consistent microphysical and scattering assumptions and that can be applied universally to multifrequency space-based radar observations (similar to the approach used in this study) are essential to demonstrate the adequacy of other mitigations. This study showed that Ka band offers independent information complementary to $\mathrm{Ku}$ band over much of the DPR sensitivity range, comprising $50 \%$ of global snowfall by volume. At intensities near and below the DPR detection threshold (about $0.5 \mathrm{~mm} \mathrm{~h}^{-1}$ ), coincident measurements at $\mathrm{Ka}$ and W band are needed to provide the same independent information about mean particle size and concentration.

Furthermore, more coordinated multifrequency radar observations as recommended in the 2017 NASA Earth Science Decadal Survey (National Academies of Sciences, Engineering, and Medicine 2018) are essential to improving the measurement of global snow from low to high rates. Ideally such future snow measurements would include $\mathrm{Ku}, \mathrm{Ka}$, and $\mathrm{W}$ radar bands with a radiometer for integrated ice water paths (IWP) and liquid water paths (LWP) quantities, and for wide-swath observations. Doppler capabilities would allow for vertical velocities of the precipitating particles. If these instruments are all on the same platform, it affords the opportunity to have a common viewpoint of the underlying falling snow conditions.

Future studies might include careful validation of GPM and CloudSat estimates with ground-based observations 
over various surface and snow-rate conditions. These comparisons must be done in a careful and coordinated matter because of the complexities of falling snow particle shapes and sensitivities due to blowing and melting snow and snowpack compaction; the differences between snow measured at the surface from ground devices and the remotely sensed falling snow, which may actually be more sensitive to snow at altitudes above Earth's surface; and because of the fields of view that differ between ground-based and satellite observations. Nevertheless, it would be worthwhile to determine if the assumptions used in the various retrieval algorithms were appropriate at regional, synoptic, or global scales.

It is vitally important to assess Earth's water cycle contributions in terms of the falling snow inputs. From the results reported here, there are subtle and obvious adjustments that must be made to the various radar and radiometer satellite datasets in order to make them comparable in an equal fashion. Since it is unlikely that the various satellite programs will adopt a common falling snow classification or common algorithm assumptions, and there is no way to address sampling and instrument differences without following the recommended adjustments outlined herein, care must be taken when comparing various satellitebased falling snow products.

Acknowledgments. Support for part of this work comes from NASA Global Precipitation Measurement (GPM) mission funding. Partial support from NASA Precipitation Measurement Mission Grants NNX16AE21G and NNX16AE87G is also acknowledged. Parts of this research by NBW were performed at the University of Wisconsin-Madison for the Jet Propulsion Laboratory, California Institute of Technology, sponsored by the National Aeronautics and Space Administration. VL recognizes support from the NextData project (http://www.nextdataproject.it) funded by the Italian Programma Nazionale della Ricerca. No conflicts of interest have been identified. The comments from three anonymous reviewers have enriched the readability of this paper.

\section{APPENDIX}

\section{List of Acronyms}

$\begin{array}{ll}\text { 2CPC } & \text { 2C-PRECIP-COLUMN } \\ \text { 2CSP } & \text { CloudSat 2C-SNOW-PROFILE } \\ \text { 2D } & \text { Two-dimensional } \\ \text { APR-2 } & \text { Airborne Precipitation Radar-2 } \\ \text { CDF } & \text { Cumulative distribution function } \\ \text { CLIM } & \text { Climate }\end{array}$

CMB GPM DPR-GMI combined algorithm

CNR- National Research Council of Italy, Institute ISAC of Atmospheric Sciences and Climate

CORRA Combined radar-radiometer algorithm (same as CMB)

CPR Cloud Profiling Radar

$\mathrm{dBZ} \quad$ Reflectivity (in decibel units)

DPR Dual-Frequency Precipitation Radar

ECMWF European Centre for Medium-Range Weather Forecasts

ERA- ECMWF interim reanalysis

Interim

FSS

GANAL Japan Meteorological Agency's Global Analysis

GCPEx Global Precipitation Measurement Cold

Season Precipitation Experiment

$\mathrm{GHz} \quad$ Gigahertz

GMI GPM Microwave Imager

GPM Global Precipitation Measurement

GPROF Goddard profiling algorithm

HS High-sensitivity KaPR scanning mode

IWP Ice water path

JAXA Japan Aerospace Exploration Agency

KaPR Ka-band Precipitation Radar on DPR

KuPR Ku-band Precipitation Radar on DPR

LWP Liquid water path

MDR Minimum detectable reflectivity

MRMS Multi-Radar Multi-Sensor

MS Matched scan for KaPR and KuPR

NASA National Aeronautics and Space Administration

NICT National Institute of Information and Communications Technology

NS Normal scan for KuPR

OE Optimal estimation

PDF Probability distribution function

PIA Path-integrated attenuation

PNS PhaseNearSurface

PSD Particle size distribution

$S \quad$ Snowfall rate

UTC Coordinated universal time

$Z \quad$ Reflectivity (in $\mathrm{mm}^{6} \mathrm{~m}^{-3}$ units)

\section{REFERENCES}

Adhikari, A., C. Liu, and M. S. Kulie, 2018: Global distribution of snow precipitation features and their properties from three years of GPM observations. J. Climate, 31, 3731-3754, https:// doi.org/10.1175/JCLI-D-17-0012.1.

Behrangi, A., M. Lebsock, S. Wong, and B. Lambrigtsen, 2012: On the quantification of oceanic rainfall using spaceborne 
sensors. J. Geophys. Res., 117, D20105, https://doi.org/10.1029/ 2012JD017979.

Boening, C., M. Lebsock, F. Landerer, and G. Stephens, 2012: Snowfall-driven mass change on the East Antarctic ice sheet. Geophys. Res. Lett., 39, L21501, https://doi.org/10.1029/ 2012GL053316.

Casella, D., G. Panegrossi, P. Sanò, A. C. Marra, S. Dietrich, B. T. Johnson, and M. S. Kulie, 2017: Evaluation of the GPM-DPR snowfall detection capability: Comparison with CloudSat-CPR. Atmos. Res., 197, 64-75, https://doi.org/10.1016/ j.atmosres.2017.06.018.

Dai, A., 2001: Global precipitation and thunderstorm frequencies. Part II: Diurnal variations. J. Climate, 14, 1112-1128, https:// doi.org/10.1175/1520-0442(2001)014<1112:GPATFP >2.0.CO;2.

Dee, D. P., and Coauthors, 2011: The ERA-Interim reanalysis: Configuration and performance of the data assimilation system. Quart. J. Roy. Meteor. Soc., 137, 553-597, https://doi.org/ 10.1002/qj.828.

Draper, D. W., D. A. Newell, F. J. Wentz, S. Krimchansky, and G. Skofronick-Jackson, 2015: The Global Precipitation Measurement (GPM) Microwave Imager (GMI): Instrument overview and early on-orbit performance. IEEE J. Sel. Top. Appl. Earth Obs. Remote Sens., 8, 3452-3462, https://doi.org/ 10.1109/JSTARS.2015.2403303.

Durden, S. L., S. Tanelli, and E. Im, 2012: Recent observations of clouds and precipitation by the airborne precipitation radar 2nd generation in support of the GPM and ACE missions. Proc. SPIE, 8523, 85230M, https://doi.org/ 10.1117/12.977574.

Ebtehaj, A. M., and C. D. Kummerow, 2017: Microwave retrievals of terrestrial precipitation over snow-covered surfaces: A lesson from the GPM satellite. Geophys. Res. Lett., 44, 61546162, https://doi.org/10.1002/2017GL073451.

Field, P. R., and A. J. Heymsfield, 2015: Importance of snow to global precipitation. Geophys. Res. Lett., 42, 9512-9520, https://doi.org/ 10.1002/2015GL065497.

Gergel, D. R., B. Nijssen, J. T. Abatzoglou, D. P. Lettenmaier, and M. R. Stumbaugh, 2017: Effects of climate change on snowpack and fire potential in the western USA. Climatic Change, 141, 287-299, https://doi.org/10.1007/s10584-0171899-y.

Grecu, M., W. S. Olson, S. J. Munchak, S. Ringerud, L. Liao, Z. Haddad, B. L. Kelley, and S. F. McLaughlin, 2016: The GPM combined algorithm. J. Atmos. Oceanic Technol., 33, 2225-2245, https://doi.org/10.1175/JTECH-D-16-0019.1.

Harpold, A. A., and M. Kohler, 2017: Potential for changing extreme snowmelt and rainfall events in the mountains of the western United States. J. Geophys. Res. Atmos., 122, 13219 13 228, https://doi.org/10.1002/2017JD027704.

Haynes, J. M., T. S. L'Ecuyer, G. L. Stephens, S. D. Miller, C. Mitrescu, N. B. Wood, and S. Tanelli, 2009: Rainfall retrieval over the ocean with spaceborne W-band radar.J. Geophys. Res., 114, D00A22, https://doi.org/10.1029/2008JD009973.

Heymsfield, A. J., A. Bansemer, C. Schmitt, C. Twohy, and M. R. Poellot, 2004: Effective ice particle densities derived from aircraft data. J. Atmos. Sci., 61, 982-1003, https://doi.org/10.1175/ 1520-0469(2004)061<0982:EIPDDF>2.0.CO;2.

_ S. Y. Matrosov, and N. B. Wood, 2016: Toward improving ice water content and snow-rate retrievals from radars. Part I: X and W bands, emphasizing CloudSat.J. Appl. Meteor. Climatol., 55, 2063-2090, https://doi.org/10.1175/JAMC-D-15-0290.1.

Holland, M. M., J. Finnis, A. P. Barrett, and M. C. Serreze, 2007: Projected changes in Arctic Ocean freshwater budgets. J. Geophys. Res., 112, G04S55, https://doi.org/ 10.1029/2006JG000354.

Hou, A. Y., and Coauthors, 2014: The Global Precipitation Measurement (GPM) mission. Bull. Amer. Meteor. Soc., 95, 701722, https://doi.org/10.1175/BAMS-D-13-00164.1.

Iguchi, T., K. Furukawa, T. Kubota, K. Yamamoto, T. Masaki, and N. Yoshida, 2018: Results of the Ka-Ku Matched Beam Experiment. 2018 IEEE Int. Geoscience and Remote Sensing Symp., Valencia, Spain, IEEE, 8323-8326, https:/doi.org/ 10.1109/IGARSS.2018.8519040.

Karl, T. R., J. M. Melillo, and T. C. Peterson, Eds., 2009: Global Climate Change Impacts in the United States. Cambridge University Press, 189 pp.

Kattsov, V. M., and J. E. Walsh, 2000: Twentieth-century trends of Arctic precipitation from observational data and a climate model simulation. J. Climate, 13, 1362-1370, https://doi.org/ 10.1175/1520-0442(2000)013<1362:TCTOAP $>2.0$.CO;2.

Kidd, C., A. Becker, G. J. Huffman, C. L. Muller, P. Joe, G. Skofronick-Jackson, and D. B. Kirschbaum, 2017: So, how much of the Earth's surface is covered by rain gauges? Bull. Amer. Meteor. Soc., 98, 69-78, https://doi.org/10.1175/BAMSD-14-00283.1.

Kneifel, S., M. S. Kulie, and R. Bennartz, 2011: A triplefrequency approach to retrieve microphysical snowfall parameters. J. Geophys. Res., 116, D11203, https://doi.org/ 10.1029/2010JD015430.

_ - A. von Lerber, J. Tiira, D. Moisseev, P. Kollias, and J. Leinonen, 2015: Observed relations between snowfall microphysics and triple-frequency radar measurements. J. Geophys. Res. Atmos., 120, 6034-6055, https://doi.org/10.1002/2015JD023156.

Kojima, M., and Coauthors, 2012: Dual-frequency precipitation radar (DPR) development on the Global Precipitation Measurement (GPM) Core Observatory. Proc. SPIE, 8528, 85281A, https://doi.org/10.1117/12.976823.

Kulie, M. S., and R. Bennartz, 2009: Utilizing space-borne radars to retrieve dry snowfall. J. Appl. Meteor., 48, 2564-2580, https:// doi.org/10.1175/2009JAMC2193.1.

_- and L. Milani, 2018: Seasonal variability of shallow cumuliform snowfall: A CloudSat perspective. Quart. J. Roy. Meteor. Soc., 144, 329-343, https://doi.org/10.1002/qj.3222.

— R. Rennartz, T. Greenwald, Y. Chen, and F. Weng, 2010: Uncertainties in microwave optical properties of frozen precipitation: Implications for remote sensing and data assimilation. J. Atmos. Sci., 67, 3471-3487, https://doi.org/10.1175/ 2010JAS3520.1.

— M. J. Hiley, R. Bennartz, S. Kneifel, and S. Tanelli, 2014: Triple frequency radar reflectivity signatures of snow: Observations and comparisons to theoretical ice particle scattering models. J. Appl. Meteor. Climatol., 53, 1080-1098, https://doi.org/ 10.1175/JAMC-D-13-066.1.

_ L. Milani, N. Wood, S. Tushaus, R. Bennartz, and T. S. L'Ecuyer, 2016: A shallow cumuliform snowfall census using spaceborne radar. J. Hydrometeor., 17, 1261-1279, https:// doi.org/10.1175/JHM-D-15-0123.1.

Kummerow, C. D., S. Ringerud, J. Crook, D. Randel, and W. Berg, 2011: An observationally generated a priori database for microwave rainfall retrievals. J. Atmos. Oceanic Technol., 28, 113-130, https://doi.org/10.1175/2010JTECHA1468.1.

—, D. L. Randel, M. S. Kulie, N.-Y. Wang, R. Ferraro, S. J. Munchak, and V. Petkovic, 2015: The evolution of the Goddard profiling algorithm to a fully parametric scheme. J. Atmos. Oceanic Technol., 32, 2265-2280, https://doi.org/10.1175/ JTECH-D-15-0039.1. 
Kuo, K., and Coauthors, 2016: The microwave radiative properties of falling snow derived from nonspherical ice particle models. Part I: An extensive database of simulated pristine crystals and aggregate particles, and their scattering properties. J. Appl. Meteor. Climatol., 55, 691-708, https://doi.org/ 10.1175/JAMC-D-15-0130.1.

Le, M., V. Chandrasekar, and S. Biswas, 2017: An algorithm to identify surface snowfall from GPM DPR observations. IEEE Trans. Geosci. Remote Sens., 55, 4059-4071, https://doi.org/ 10.1109/TGRS.2017.2687420.

Leinonen, J., and D. Moisseev, 2015: What do triple-frequency radar signatures reveal about aggregate snowflakes? J. Geophys. Res. Atmos., 120, 229-239, https://doi.org/10.1002/ 2014JD022072.

—_, S. Kneifel, D. Moisseev, J. Tyynela, S. Tanelli, and T. Nousiainen, 2012: Evidence of nonspheroidal behavior in millimeter-wavelength radar observations of snowfall. J. Geophys. Res., 117, D18205, https://doi.org/10.1029/ 2012JD017680.

Lettenmaier, D. P., D. Alsdorf, J. Dozier, G. J. Huffman, M. Pan, and E. F. Wood, 2015: Inroads of remote sensing into hydrologic science during the WRR era. Water Resour. Res., 51, 7309-7342, https://doi.org/10.1002/2015WR017616.

Levizzani, V., S. Laviola, and E. Cattani, 2011: Detection and measurement of snowfall from space. Remote Sens., 3, 145166, https://doi.org/10.3390/rs3010145.

Liao, L., R. Meneghini, A. Tokay, and L. F. Bliven, 2016: Retrieval of snow properties for $\mathrm{Ku}$ - and $\mathrm{Ka}$-band dual-frequency radar. J. Appl. Meteor. Climatol., 55, 1845-1858, https://doi.org/ 10.1175/JAMC-D-15-0355.1.

Liu, G., 2008a: Deriving snow cloud characteristics from CloudSat observations. J. Geophys. Res., 113, D00A09, https://doi.org/ 10.1029/2007JD009766.

— 2008b: A database of microwave single-scattering properties for nonspherical ice particles. Bull. Amer. Meteor. Soc., 89, 1563-1570, https://doi.org/10.1175/2008BAMS2486.1.

Locatelli, J. D., and P. V. Hobbs, 1974: Fall speeds and masses of solid precipitation particles. J. Geophys. Res., 79, 2185-2197, https://doi.org/10.1029/JC079i015p02185.

Maahn, M., C. Burgard, S. Crewell, I. V. Gorodetskaya, S. Kneifel, S. Lhermitte, K. Van Tricht, and N. P. M. van Lipzig, 2014: How does the spaceborne radar blind zone affect derived surface snowfall statistics in polar regions? J. Geophys. Res. Atmos., 119, 13 604-13 620, https://doi.org/ 10.1002/2014JD022079.

Marchand, R., G. G. Mace, T. Ackerman, and G. L. Stephens, 2008: Hydrometeor detection using CloudSat-An Earth-orbiting 94-GHz cloud radar. J. Atmos. Oceanic Technol., 25, 519-533, https://doi.org/10.1175/2007JTECHA1006.1.

Margulis, S. A., G. Cortés, M. Girotto, and M. Durand, 2016: A Landsat-era Sierra Nevada snow reanalysis (1985-2015). J. Hydrometeor., 17, 1203-1221, https://doi.org/10.1175/ JHM-D-15-0177.1.

Matrosov, S. Y., 2019: Comparative evaluation of snowfall retrievals from the CloudSat W-band radar using ground-based weather radars. J. Atmos. Oceanic Technol., 36, 101-111, https://doi.org/10.1175/JTECH-D-18-0069.1.

_- , and A. Battaglia, 2009: Influence of multiple scattering on CloudSat measurements in snow: A model study. Geophys. Res. Lett., 36, L12806, https://doi.org/10.1029/ 2009GL038704.

Mitchell, D. L., 1996: Use of mass- and area-dimensional power laws for determining precipitation particle terminal velocities.
J. Atmos. Sci., 53, 1710-1723, https://doi.org/10.1175/ 1520-0469(1996)053<1710:UOMAAD>2.0.CO;2.

National Academies of Sciences, Engineering, and Medicine, 2018: Thriving on Our Changing Planet: A Decadal Strategy for Earth Observation from Space. National Academies Press, 716 pp., https://doi.org/10.17226/24938.

Olson, W. S., and Coauthors, 2016: The microwave radiative properties of falling snow derived from nonspherical ice particle models. Part II: Initial testing using radar, radiometer and in situ observations. J. Appl. Meteor. Climatol., 55, 709-722, https://doi.org/10.1175/JAMC-D-15-0131.1.

Palerme, C., J. E. Kay, C. Genthon, T. L'Ecuyer, N. B. Wood, and C. Claud, 2014: How much snow falls on the Antarctic ice sheet? Cryosphere, 8, 1577-1587, https://doi.org/10.5194/tc-81577-2014.

Panegrossi, G., J.-F. Rysman, D. Casella, A. C. Marra, P. Sano, and M. S. Kulie, 2017: CloudSat-based assessment of GPM Microwave Imager snowfall observation capabilities. Remote Sens., 9, 1263, https://doi.org/10.3390/rs9121263.

Rodell, M., and Coauthors, 2015: The observed state of the water cycle in the early twenty-first century. J. Climate, 28, 82898318, https://doi.org/10.1175/JCLI-D-14-00555.1.

Rodgers, C. D., 2000: Inverse Methods for Atmospheric Sounding: Theory and Practice. Series on Atmospheric, Oceanic and Planetary Physics, Vol. 2, World Scientific, 238 pp.

Sekhon, R. S., and R. C. Srivastava, 1970: Snow size spectra and radar reflectivity. J. Atmos. Sci., 27, 299-307, https://doi.org/ 10.1175/1520-0469(1970)027<0299:SSSARR > 2.0.CO;2.

Sims, E. M., and G. Liu, 2015: A parameterization of the probability of snow-rain transition. J. Hydrometeor., 16, 1466-1477, https://doi.org/10.1175/JHM-D-14-0211.1.

Skofronick-Jackson, G. M., B. T. Johnson, and S. J. Munchak, 2013: Detection thresholds of falling snow from satellite-borne active and passive sensors. IEEE Trans. Geosci. Remote Sens., 51, 4177-4189, https://doi.org/10.1109/TGRS.2012.2227763.

_ , and Coauthors, 2015: Global Precipitation Measurement Cold Season Precipitation Experiment (GCPEx): For measurement sake let it snow. Bull. Amer. Meteor. Soc., 96, 1719-1741, https:// doi.org/10.1175/BAMS-D-13-00262.1.

_ , and Coauthors, 2017: The Global Precipitation Measurement (GPM) for science and society. Bull. Amer. Meteor. Soc., 98, 16791695, https://doi.org/10.1175/BAMS-D-15-00306.1.

Stephens, G. L., and Coauthors, 2002: The CloudSat mission and the A-Train: A new dimension of space-based observations of clouds and precipitation. Bull. Amer. Meteor. Soc., 83, 17711790, https://doi.org/10.1175/BAMS-83-12-1771.

_ , and Coauthors, 2008: CloudSat mission: Performance and early science after the first year of operation. J. Geophys. Res., 113, D00A18, https://doi.org/10.1029/2008JD009982.

Tanelli, S., S. L. Durden, E. Im, K. S. Pak, D. G. Reinke, P. Partain, J. M. Haynes, and R. T. Marchand, 2008: CloudSat's cloud profiling radar after two years in orbit: Performance, calibration, and processing. IEEE Trans. Geosci. Remote Sens., 46, 3560-3573, https://doi.org/10.1109/TGRS.2008.2002030.

Tang, G., Y. Wen, J. Gao, D. Long, Y. Ma, W. Wan, and Y. Hong, 2017: Similarities and differences between three coexisting spaceborne radars in global rainfall and snowfall estimation. Water Resour. Res., 53, 3835-3853, https://doi.org/10.1002/2016WR019961.

Toyoshima, K., H. Masunaga, and F. A. Furuzawa, 2015: Early evaluation of $\mathrm{Ku}-$ and Ka-band sensitivities for the Global Precipitation Measurement (GPM) Dual-Frequency Precipitation Radar (DPR). SOLA, 11, 14-17, https://doi.org/10.2151/ sola.2015-004. 
Turk, J., 2016: CloudSat-GPM coincidence dataset, version 1C. NASA Tech Rep., 18 pp., https://pmm.nasa.gov/sites/default/ files/document_files/CSATGPM_COIN_ATBD.pdf.

Tyynela, J., J. Leinonen, D. Moisseev, and T. Nousiainen, 2011: Radar backscattering from snowflakes: Comparison of fractal, aggregate and soft-spheroid models. J. Atmos. Oceanic Technol., 28, 1365-1372, https://doi.org/10.1175/JTECH-D11-00004.1.

Wentz, F. J., and D. W. Draper, 2016: On-orbit absolute calibration of the global precipitation measurement microwave imager. J. Atmos. Oceanic Technol., 33, 1393-1412, https://doi.org/ 10.1175/JTECH-D-15-0212.1.

Wilson, D. R., and S. P. Ballard, 1999: A microphysically based precipitation scheme for the UK Meteorological Office Unified Model. Quart. J. Roy. Meteor. Soc., 125, 1607-1636, https:// doi.org/10.1002/qj.49712555707.

Wood, N. B., 2011: Estimation of snow microphysical properties with application to millimeter-wavelength radar retrievals for snowfall rate. Ph.D. dissertation, Colorado State University, Fort Collins, CO, 248 pp., http://hdl.handle.net/10217/48170. , and T. S. L'Ecuyer, 2013: Level 2C snow profile process description and interface control document, version 0. CloudSat Project: A NASA Earth System Science Pathfinder Mission, 23 pp., accessed 19 July 2017, http://www.cloudsat.cira.colostate.edu/sites/
default/files/products/files/2C-SNOW-PROFILE_PDICD.P_ R04.20130210.pdf.

— — - A. J. Heymsfield, G. L. Stephens, D. R. Hudak, and P. Rodriguez, 2014: Estimating snow microphysical properties using collocated multisensor observations. J. Geophys. Res. Atmos., 119, 8941-8961, https://doi.org/10.1002/2013JD021303.

,,--- , and,- 2015 : Microphysical constraints on millimeter-wavelength scattering properties of snow particles. J. Appl. Meteor. Climatol., 54, 909-931, https://doi.org/10.1175/ JAMC-D-14-0137.1.

Wrzesien, M. L., M. T. Durand, T. M. Pavelsky, S. B. Kapnick, Y. Zhang, J. Guo, and C. K. Shum, 2018: A new estimate of North American mountain snow accumulation from regional climate model simulations. Geophys. Res. Lett., 45, 1423-1432, https://doi.org/10.1002/2017GL076664.

Yin, M., G. Liu, R. Honeyager, and F. J. Turk, 2017: Observed differences of triple-frequency radar signatures between snowflakes in stratiform and convective clouds. J. Quant. Spectrosc. Radiat. Transfer, 193, 13-20, https://doi.org/10.1016/ j.jqsrt.2017.02.017.

Zhang, J., and Coauthors, 2016: Multi-Radar Multi-Sensor (MRMS) quantitative precipitation estimation: Initial operating capabilities. Bull. Amer. Meteor. Soc., 97, 621-638, https://doi.org/10.1175/ BAMS-D-14-00174.1. 